\title{
The Partially Free Draining Effect and Unperturbed Chain Dimensions of Cellulose, Amylose, and their Derivatives
}

\author{
Kenji Kamide and Yukio MiYazaKi \\ Textile Research Laboratory, Asahi Chemical Industry Company, Ltd., \\ Takatsuki, Osaka 569, Japan.
}

(Received November 7, 1977)

\begin{abstract}
In order to estimate the unperturbed chain dimensions of cellulose, amylose and their derivatives, the literature data available for fourteen polymers have been analyzed systematically. The draining parameter $X$ defined in Kurata-Yamakawa theory was evaluated by various methods and was found to be less than 2 in most instances, regardless of the methods employed. The polymers exhibited often a significant non-gaussian nature expressed by a negative value of $a_{2} \equiv \mathrm{d} \ln \left(\left\langle S^{2}\right\rangle_{0} / M\right) / \mathrm{d} \ln M$, where $\left\langle S^{2}\right\rangle_{0}^{1 / 2}$ is the radius of gyration of a polymer chain in the unperturbed state and $M$ is the molecular weight. Flory's viscosity parameter $\Phi$ always showed a positive $M$ dependence as described by $a_{\Phi} \equiv \mathrm{d} \ln \Phi / \mathrm{d} \ln M>0$. The latter finding is compatible with low $X$ values. Two new methods for estimating $A(\equiv 6$ $\left.\left(\left\langle S^{2}\right\rangle_{0} / M\right)^{1 / 2}\right)$ in the case of $a_{2} \neq 0$ and $a_{\Phi} \neq 0$ were proposed as generalization of the Baumann plot and the Stockmayer-Fixman (SF) plot. The same $A$ values were obtained by thermodynamic and hydrodynamic approaches. The original SF plot proved unsuccessful and underestimated $A$ by about $50 \%$. Cellulose, amylose, and their derivatives have large unperturbed chain dimensions and their expansion factors are not much larger than unity even in good solvents.
\end{abstract}

KEY WORDS Cellulose / Amylose / Cellulose Derivatives / Amylose Derivatives / Draining Effect / Unperturbed Chain Dimension / NonGaussian Nature /

As is well-known, dilute solutions of cellulose, amylose and their derivatives have remarkable features as summarized below. ${ }^{1}$

(1) The limiting viscosity number $[\eta]$ of these polymers is occasionally considerably large as compared with that of typical vinyl-type polymers in a good solvent at a given molecular weight $M$, and has a large negative dependence on temperature.

(2) The slope of the log-log plot of $[\eta]$ against $M$, or the exponent $a$ in the Mark-HouwinkSakurada (MHS) equation (eq 4) lies often between $0.8-1.0$ (see Table III).

(3) In a treatment of the solution properties of these polymers (method 2B in this paper), the excluded volume parameter $z$ are evaluated from the penetration function $\phi$ (eq 21), and are found to be less than unity. This indicates that the expansion factor $\alpha_{\mathrm{s}}$ is only slightly larger than unity, and the solvents involved are not good.

(4) If the unperturbed chain dimensions are evaluated from $\alpha_{\mathrm{s}}$ thus obtained and from the experimental values of the radius of gyration $\left\langle S^{2}\right\rangle^{1 / 2}$, the conformation parameter $\sigma$ (eq 29) is found to be much larger than those of vinyl polymers. This means that the cellulose and amylose chains are very stiff.

(5) In another treatment, the unperturbed chain dimensions are estimated from the experimental data on $[\eta]$ and $M($ Method 2E) through use of the Stockmayer-Fixman equation (eq 40) or similar equations. The result shows that cellulose and amylose chains are quite flexible and the solvents involved are good.

(6) The Flory viscosity parameter (eq 2) is assumed, in this treatment, to show no significant trend of the molecular weight dependence, and hence the partially free draining effect on $[\eta]$ to be 


\section{K. KAMIDE and Y. MiYAZAKI}

negligible.

(7) In contrast to the assumption (6), the parameter $\Phi$ depends on $M$ appreciably and the draining effect can never be ignored, at least, for cellulose trinitrate. The above-mentioned features are, of course, mutually inconsistent, and at the present there are two conflicting theoretical views concerning the flexibility of the polymer chains and the role of volume effect and draining effect on $[\eta]$ : the polymer chains are of typical flexibility as are the vinyl polymer chains, and a large value of $[\eta]$ can be interpreted in terms of the excluded volume effect (view point $\mathrm{A}$ ); the polymer chains are semi- or inflexible and their large unperturbed chain dimension is mainly responsible for a large [ $\eta]$ (view point B). The former has it's foundation on the "two-paramerter" theory. ${ }^{2}$ These inconsistences have not been solved for these fifteen years in spite of the rapid accumlation of experimental data, especially from 1960-1971, and this is one of the most outstanding problems yet unsolved in the science of high polymer solutions.

In this paper we intend to solve this problem by analyzing the experimental data in the literature available for this purpose in a very rigorous and systematical manner and to show that view point $B$ is preferable.

\section{THEORETICAL BACKGROUND}

\section{A. Evaluation of Partial Draining Effect}

The draining parameter $X$ is defined by the relation $^{3}$ :

$$
X=(1 / 2)(6 / \pi)^{1 / 2}\left(b / a^{\prime}\right) N^{1 / 2}
$$

where $a^{\prime}$ is the length of a link and $b$ is the diameter of a hydrodynamic segment, and $N$ the number of links connecting segments in one molecule. $X$ can be evaluated by using the following methods:

\section{Method $1 A$}

The Flory viscosity parameter $\Phi$ is related to the limiting viscosity number $[\eta]$, the weight-average molecular weight $M_{w}$ and the $z$-average radius of gyration $\left\langle S^{2}\right\rangle_{z}$ as

$$
\begin{aligned}
\Phi & \equiv[\eta] M_{w} /\left\langle S^{2}\right\rangle_{z}^{3 / 2} 6^{3 / 2} q_{w, z} \\
& =\Phi(X) \alpha_{\mathrm{s}}^{-(3-n(X))} \\
\alpha_{\mathrm{s}} & =\left\langle S^{2}\right\rangle^{1 / 2}\left\langle S^{2}\right\rangle_{0}^{1 / 2}
\end{aligned}
$$

where $q_{w, z}$ is a correcting factor for the polymolecularity of the sample. $\Phi(X)$ and $n(X)$ are functions of $X$ defined by Kurata and Yamakawa (KY) and $\Phi_{0}(X)$ denotes $\Phi(X)$ at $\alpha_{s}=1 .\left\langle S^{2}\right\rangle_{0}{ }^{1 / 2}$ denotes $\left\langle S^{2}\right\rangle^{1 / 2}$ in the unperturbed state $(i . e$. , $\left.\alpha_{s}=1\right) . \quad X$ can be calculated from data of [ $\left.\eta\right]$, $M_{w},\left\langle S^{2}\right\rangle_{z}$ and $\alpha_{z}$, using eq 2 . In this paper, the Schulz-Zimm type distribution was assumed for the polymer samples and $\Phi_{0}(\infty)=2.87 \times 10^{23}$ was utilized. Here $[\eta]$ is expressed in terms of $\mathrm{cm}^{3} / \mathrm{g}$.

\section{Method $1 B$}

The molecular weight dependence of the limiting viscosity number can be expressed by the MarkHouwink-Sakurada (MHS) equation,

$$
[\eta]=K_{\mathrm{m}} M^{a}
$$

where $K_{m}$ and $a$ are parameters characteristic of a given polymer-solvent system and temperature. The exponent $a$ in eq 4 can be devided into three parts $^{4}$

$$
a=0.5+\nu(X)+n(X) \varepsilon+1.5 a_{2}
$$

where

$$
\begin{aligned}
\varepsilon & =\mathrm{d} \ln \alpha_{\mathrm{s}} / \mathrm{d} \ln M \\
a_{2} & =\mathrm{d} \ln \left(\left\langle S^{2}\right\rangle_{0} / M\right) / \mathrm{d} \ln M
\end{aligned}
$$

$\nu(X)$ appearing in eq 5 has the significance defined in the KY treatment. $\varepsilon$ reflects the volume effect and $a_{2}$ represents the non-gaussian nature of the unperturbed polymeric chain.

When the sedimentation constant $s_{0}$ is related to the molecular weight by

$$
s_{0}=K_{\mathrm{s}} M^{a_{\mathrm{s}}}
$$

where $s_{0}$ is the sedimentation coefficient at infinite dilution and $K_{\mathrm{s}}$ and $a_{\mathrm{s}}$ are parameters characteristic of a given polymer-solvent system, it can be readily shown that the exponent $a_{\mathrm{s}}$ in eq 8 is given by

$$
a_{\mathrm{s}}=0.5-\mu(X)+(1-m(X)) \varepsilon-0.5 a_{2}-\varepsilon
$$

$\mu(X)$ as well as $m(X)$ was defined in the $\mathrm{KY}$ theory. Combination of eq 5 and 9 yields. $^{5}$

$3 a_{\mathrm{s}}+a-2.0=\nu(X)-3 \mu(X)+(n(X)-3 m(X)) \varepsilon$

Both $X$ and $\varepsilon$ should be determined from the measurement of $a$ and $a_{\mathrm{s}}$ by using eq 5 and 10 when the value of $a_{2}$ is practically zero, or estimated by some other absolute method. 


\section{Method $1 C$}

The molecular weight dependence of the diffusion constant at infinite dilution, $D_{0}$ is expressed as

$$
D_{0}=K_{\mathrm{d}} M^{a_{\mathrm{d}}}
$$

where $K_{\mathrm{d}}$ and $a_{\mathrm{d}}$ are dependent on a given polymersolvent system and the exponent $a_{\mathrm{d}}$ is given by eq $12 .^{5}$

$$
a-3 a_{\mathrm{d}}+1=\nu(X)-3 \mu(X)+(n(X)-3 m(X)) \varepsilon
$$

On substituting numerical values for $a, a_{\mathrm{d}}$, and $a_{2}$ in eq 5 and 12 , values of $X$ and $\varepsilon$ are obtainable from experimental data.

\section{Method 1D}

The molecular weight dependence of the radius of gyration of polymer chain is expressed empirically by

$$
\left\langle S^{2}\right\rangle^{1 / 2}=K_{\lambda} M^{(\lambda+1) / 2}
$$

where

$$
\lambda=\mathrm{d} \ln \left(\left\langle S^{2}\right\rangle / M\right) / \mathrm{d} \ln M
$$

$K_{\lambda}$ and $\lambda$ depend on a given polymer-solvent system, and exponent $\lambda$ is given by

$$
\begin{aligned}
& a-(3 \lambda+1) / 2 \\
& \quad=\nu(X)-(3-n(X))\left((\lambda+1) / 2-0.5-0.5 a_{2}\right)
\end{aligned}
$$

Equation 15 gives a method for evaluating $X$ directly from the data of $a, \lambda$, and $a_{2}$. At the limit of $X=\infty$ and if $n(X)=2.43$ is replaced by 3 to a first approximation, eq 15 is reduced to the familiar expression,

$$
a=(3 \lambda+1) / 2
$$

\section{Method $1 E$}

The concentration dependence of the sedimentation coefficient is expressed by the empirical equation of the form:

$$
(1 / s)=\left(1 / s_{0}\right)\left(1+k_{\mathrm{s}} C\right)
$$

where $s$ is the sedimentation coefficient at concentration $C$, and $k_{\mathrm{s}}$ a parameter related to [ $\left.\eta\right]$ by the formula ${ }^{6}$

$$
\begin{aligned}
k_{\mathrm{s}} /[\eta] & =(55 / 8) N_{\mathrm{A}} \\
& \times\left(\Phi_{0}(X)^{1 / 3} P_{0}(X)^{-1}\right)\left(16200 \pi^{2}\right)^{-1} \alpha_{\mathrm{s}}^{(m(X)-3 n(X))}
\end{aligned}
$$

where $N_{\mathrm{A}}$ is the Avogadro number and $P_{0}(X)$ is a function of $X$ which was defined in the theory of
KY. The term $\alpha_{\mathrm{s}}^{(m(X)-3 n(X))}$ in the above equation can be approximated as unity under the conditions of $\alpha_{\mathrm{s}}<2$ within an error less than $10 \%$. Hence, by eq 17 we can determine $X$ from data of limiting viscosity number and concentration dependence of sedimentation coefficient, provided that $X<1$.

\section{Method $1 F$}

Equation 14 can be rewritten with the aid of eq 6 and 7 as

$$
\lambda=a_{2}+2 \varepsilon
$$

eq 18 affords us a method for estimating $\varepsilon$ from $\lambda$ and $a_{2}$. Combining eq 18 with eq 5 , one obtains

$$
a-0.5-1.5 \lambda=\nu(X)+(n(X)-3) \varepsilon
$$

Then, substituting of eq 19 into eq 10 gives

$$
\begin{aligned}
& 3 a_{\mathrm{s}}+a-2.0=\nu(X)-3 \mu(X) \\
& \quad+(n(X)-3 m(X))(0.5+1.5 \lambda+\nu(X)-a) /(3-n(X))
\end{aligned}
$$

The draining parameter $X$ and $\varepsilon$ can be determined from measurement of $a, a_{\mathrm{s}}$, and $\lambda$ by use of eq 19 and 20.

In the method 1A the value of $\alpha_{\mathrm{s}}$ should be determined in advance. Unfortunately, there have been only few light scattering measurements of $\left\langle S^{2}\right\rangle_{0}{ }^{1 / 2}$ for cellulose, amylose and their derivatives in theta $\theta$ solutions. In addition, there is the possibility that the value of $\left\langle S^{2}\right\rangle_{0}{ }^{1 / 2}$ depends strongly on the solvent nature. Hence, we have to evaluate $\alpha_{\mathrm{s}}$ indirectly for cellulose solutions. For this reason, $\alpha_{\mathrm{s}}$ is determined from the penetration function $\phi$ which is defined by ${ }^{7}$

$$
\phi \equiv \bar{z} h_{0}(\bar{z})=0.746 \times 10^{-25} A_{2} M^{2} \mid\left\langle S^{2}\right\rangle^{3 / 2}
$$

where

$$
\begin{aligned}
& \bar{z}=z / \alpha^{3} \simeq z / \alpha_{\mathrm{s}}{ }^{3} \\
& z=\left(1 / 8 \pi^{3 / 2}\right) B A^{-3} M^{1 / 2} \\
& \alpha=\left\langle R^{2}\right\rangle^{1 / 2} /\left\langle R^{2}\right\rangle_{0}{ }^{1 / 2} \\
& A=\left(\left\langle R^{2}\right\rangle_{0} / M\right)^{1 / 2} \\
& B=\beta / m_{0}{ }^{2}
\end{aligned}
$$

$A_{2}$ is the second virial coefficient, $\mathrm{A}$ and $\mathrm{B}$, shortand long-range interactions, $\left\langle R^{2}\right\rangle$ and $\left\langle R^{2}\right\rangle_{0}$, the mean-square end-to-end distances of the chain in the perturbed and unperturbed state, $\beta$, the binary cluster integral, representing the interaction be- 


\section{K. KAMIDE and Y. MiYAZAKI}

tween the non-bonded segments of polymer chains, $m_{0}$, molecular weight of a segment. According to the Kurata-Fukatsu-Sotobayashi-Yamakawa (KFSY) theory, ${ }^{8} h_{0}(\bar{z})$ is related to $\bar{z}$ by

$$
\bar{z} h_{0}(\bar{z})=(1 / 5.047)\left\{1-(1+0.683 \bar{z})^{-7.39}\right\}
$$

The value of $z$ can be determined from experimental data on $A_{2}, M$ and $\left\langle S^{2}\right\rangle_{0}$ by using eq 21 and 27. $\alpha_{\mathrm{s}}$ is related to $z$ through $^{8}$

$$
\alpha_{\mathrm{s}}^{3}-1=1.78 z
$$

Combination of eq 22 and eq 28 furnishes a method for estimating $\alpha_{\mathrm{s}}$ (accordingly, $\alpha$ ) from $\bar{z}$. The parameter (1.78) in eq 28 differs slightly depending on the theory, but this variation does not afford a significant change in $\alpha_{\mathrm{s}}$ in the range $\alpha_{\mathrm{s}}{ }^{3}<2$.

\section{B. Evaluation of Unperturbed Chain Dimensions}

The unperturbed chain dimensions can be expressed in terms of a short-range interaction parameter $A$ in eq 25 . The conformation parameter $\sigma$ and characteristic ratio $C_{\infty}$ are defined by eq 29 and 30 , respectively.

$$
\begin{aligned}
\sigma & =\left(\left\langle R^{2}\right\rangle_{0} /\left\langle R^{2}\right\rangle_{0 \mathrm{f}}\right)^{1 / 2}=A / A_{\mathrm{f}} \\
C_{\infty} & =A_{\infty}{ }^{2} M_{\mathrm{b}} / l^{2}
\end{aligned}
$$

where $\left\langle R^{2}\right\rangle_{0 \mathrm{f}}^{1 / 2}\left(\equiv A_{\mathrm{f}} M^{1 / 2}\right)$ is the root mean-square end-to-end distance of a hypothetical chain with free internal rotation, $A_{\infty}$, the assymptotic value of $A$ at infinite molecular weight (in the case of $a_{2} \neq$ $0, A$ value at $M_{w}=1 \times 10^{5}$ is utilized as $\left.A_{\infty}\right), M_{\mathrm{b}}$, the mean molecular weight per skeletal bond and $l$, the mean bond length ( $=5.47 \AA$ for cellulose derivatives and $4.25 \AA$ for amylose derivatives). Here the $\mathrm{C} 1$ ring conformation is assumed for the standard $\beta$-D-glucose residue. The methods of estimating $A$ are summarized below.

\section{Method 2A}

When the unperturbed radius of gyration $\left\langle S^{2}\right\rangle_{0}{ }^{1 / 2}$ can be measured in a Flory's theta solvent, where $A_{2}=0, z=0$ and $\alpha_{\mathrm{s}}=1, A$ is directly evaluated by use of eq 25 .

\section{Method 2B}

When the linear expansion factor $\alpha_{\mathrm{s}}$ is determined from the function $\psi$ the unperturbed dimension, $\left\langle S^{2}\right\rangle_{0}^{1 / 2}$, accordingly $A$, can be evaluated from the experimental data of $\left\langle S^{2}\right\rangle^{1 / 2}$ in nonideal solvents using eq 3 . Only in the range $\alpha_{\mathrm{s}}^{3}>2$, the value of $\alpha_{\mathrm{s}}$ depends significantly on the theory of $A_{2}$ adopted. $\left\langle S^{2}\right\rangle_{0}$ can be transformed to $\left\langle R^{2}\right\rangle_{0}$ by use of eq 31 .

$$
\left\langle R^{2}\right\rangle_{0}=6\left\langle S^{2}\right\rangle_{0}
$$

In this paper, eq 31 is applied even in the case of $a_{2} \neq 0$.

\section{Method 2C}

If the factor 1.78 in eq 28 is replaced by 2.0 , which is widely used in practical cases, we obtain ${ }^{9}$

$$
\alpha_{\mathrm{s}}{ }^{3}-1=2.0 z
$$

Equation 23 can be recast with the aid of eq $28^{\prime}$ as

$$
\left\langle S^{2}\right\rangle^{3 / 2} / M^{3 / 2}=A^{3 / 2} / 6^{3 / 2}+\left(1 / 4 \pi^{3 / 2}\right) B M^{1 / 2}
$$

Plots of $\left\langle S^{2}\right\rangle^{3 / 2} / M^{3 / 2}$ against $M^{1 / 2}$ (the Baumann plot ${ }^{10}$ enables us to evaluate $A$ from the intercept at $M^{1 / 2}=0$. In this case, the unperturbed chain is assumed to be a gaussian chain. The experimental data of the $z$-average radius of gyration $\left\langle S^{2}\right\rangle_{z}{ }^{1 / 2}$ were converted to the weight-average radius of gyration $\left\langle S^{2}\right\rangle_{w}{ }^{1 / 2}$.

\section{Method 2D}

In the case of $a_{2} \neq 0$, the Baumann plot is not applicable and the following equation can be used in place of eq 32 .

$$
\left\langle S^{2}\right\rangle^{3 / 2} / M^{3\left(1+a_{2}\right) / 2}=K_{0}^{3 / 2}+\left(1 / 4 \pi^{3 / 2}\right) B M^{\left(1-3 a_{2}\right) / 2}
$$

where

$$
K_{0}=\left(\left\langle S^{2}\right\rangle_{0} / M\right) / M^{a_{2}}
$$

By use of eq 33 the plots of $\left\langle S^{2}\right\rangle^{3 / 2} / M^{3\left(1+a_{2}\right) / 2}$ against $M^{\left(1-3 a_{2}\right) / 2}$ (Baumann-Kamide-Miyazaki (BKM) plot) for a given solvent should result in a straight line and its extrapolation to $M^{1 / 2}=0$ should give the $K_{0}^{3 / 2}$ value and accordingly $K_{0}$.

\section{Method 2E}

According to the KY theory, ${ }^{3}$ the limiting viscosity number $[\eta]$ is given by eq 35

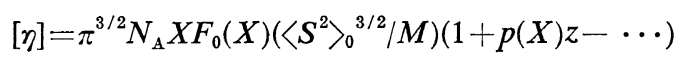

where $F_{0}(X)$ and $p(X)$ are functions of the draining parameter $X$. When $a_{2}=0$, eq 35 can be rewritten on the basis of the Kawai-Kamide treatment ${ }^{11}$ as

$[\eta] / f(X) M^{1 / 2}=K+\Phi_{0}(X) p(X)(3 / 2 \pi)^{3 / 2} B M^{1 / 2}-\cdots$

where

$$
K=\Phi_{0}\left(X_{0}\right) A^{3}
$$




$$
f(X)=X F_{0}(X) / X_{0} F_{0}\left(X_{0}\right)
$$

The value of $X_{0}$ in eq 38 is determined by the equation:

$$
\nu\left(X_{0}\right)=\varepsilon\left(3-n\left(X_{0}\right)\right)
$$

The value of $K$ (accordingly, $A$ ) can be determined as an intercept at $M^{1 / 2} \rightarrow 0$ of the plot of $[\eta] / f(X) M^{1 / 2}$ against $M^{1 / 2}$. The well-known Stockmayer-Fixman equation ${ }^{12}$

$$
[\eta] / M^{1 / 2}=K+2(3 / 2 \pi)^{3 / 2} \Phi_{0}(\infty) B M^{1 / 2}
$$

is derived from eq 36 by putting $X=\infty$ and neglecting terms higher than $M^{1 / 2}$. It should be noticed here that eq 40 does not hold when $a_{2} \neq 0$ and/or when $X$ is finite or at least $X<X_{0}$. In the latter case, $a_{\Phi}$ in eq 44 no longer becomes zero. The above-mentioned limitations to eq 40 have not been carefully taken into consideration when this equation was applied to cellulose and its derivative solutions. In the case of $a_{2}=0$ and $a_{\Phi}=0$, the plot of $[\eta] / M^{1 / 2}$ vs. $M^{1 / 2}$ (SF plot), obtained from experimental data for a given polymer, should give a straight line and it's intercept at $M^{1 / 2} \rightarrow 0$ and it's slope should give $K$ and $B$, respectively. In this paper, after the correction of molecular weight distribution of the sample was applied to $K, A$ was evaluated from $K$ value using eq $37\left(X_{0}=\infty\right)$. Here, $\Phi_{0}(\infty)=2.87 \times 10^{23}$ was adopted.

\section{Method $2 F$}

The following relation holds between parameters $K_{\mathrm{m}}, a$ in eq $4, a_{2}$ and $X$.

$$
\begin{array}{r}
-\log K_{\mathrm{m}}+\log \left[1+2\left(a-0.5-\Delta-1.5 a_{2}\right)^{-1}-2^{-1}\right] \\
=-\log K f(X)+\left(a-0.5-\Delta-1.5 a_{2}\right) \log M_{0}
\end{array}
$$

Equation 41 and similar equations were derived by Kamide, Kawai, and their coworkers. ${ }^{13-17} \Delta$ in eq 41 is defined by eq 42 .

$$
\begin{aligned}
\Delta & =\nu(X)-\nu\left(X_{0}\right) \\
& =\nu(X)-\varepsilon\left(3-n\left(X_{0}\right)\right)
\end{aligned}
$$

$M_{0}$ is a parameter depending on the molecular weight range, $M_{1}-M_{2}$, to which eq 4 applies. In a case where the draining effect is negligible, the geometric mean, $\left(M_{1} M_{2}\right)^{1 / 2}$, can be regarded, to a fairly good approximation, as $M_{0} . \quad K$ can be determined from $K_{\mathrm{m}}, a, X$ (accordingly, $\Delta$ ) and $a_{2}$. However, the accuracy of estimation of $X$ by eq 41 is not so good. Putting $a_{2}=0$ and $\Delta=0$ in eq
41, we obtain:

$$
\begin{gathered}
-\log K_{\mathrm{m}}+\log \left[1+2\left\{(a-0.5)^{-1}-2\right\}^{-1}\right] \\
=-\log K+(a-0.5) \log M_{0}
\end{gathered}
$$

Equation 43 is, in principle, equivalent to eq 40 . By use of eq 41, $K$ (accordingly, $A$ ) can be evaluated from experimental the data of $K_{\mathrm{m}}, a, M_{0}$, provided that $a_{2}=0$ and $a_{\Phi}=0$ (i.e., $X \simeq \infty$ ). It has been ascertained that eq 41 is quite useful for estimating the $K$ value of vinyl-type polymers. ${ }^{18}$

\section{Method 2G}

Equation 2 can be rearranged as:

$$
[\eta]=6^{3 / 2} \Phi\left(\left\langle S^{2}\right\rangle_{0} / M\right)^{3 / 2} M^{1 / 2} \alpha_{\mathrm{s}}^{3}
$$

As will be demonstrated later (Fig. 5), $\Phi$ of cellulose, amylose and their derivatives in dilute solutions reveals a large molecular weight dependence. This can be interpreted as another indication of the draining effect. Thus, the molecular weight dependence of $\Phi$ is empirically approximated by eq 44

$$
\Phi=K_{\Phi} M^{a} \Phi
$$

where $K_{\Phi}$ and $a_{\Phi}$ are parameters characteristic of a polymer-solvent system and the molecular weight range, in which eq 44 holds. $a_{\Phi}$ is given by

$$
a_{\Phi}=[\nu(X)-\varepsilon(3-n(X))]_{\mathrm{Av}}
$$

It is clear that for $X_{0} a_{\Phi}$ becames essentially zero and $a_{\Phi} \simeq \Delta$ (see, eq 42). The right-hand side term in eq 45 is a kind of average value of $\nu(X)-$ $\varepsilon(3-n(X))$ over the molecular weight range concerned.

Combination of eq 2, 34 and 44 leads to the equation of $[\eta]$ for the polymer solution in which $a_{2} \neq 0$ and $a_{\Phi} \neq 0$ hold, as is the case of cellulose, amylose and their derivatives, given by eq 46 .

$[\eta] / M^{0.5+a_{\Phi}+1.5 a_{2}}=6^{3 / 2} K_{\Phi} K_{0}^{3 / 2}+0.66 K_{\Phi} B M^{\left(1-3 a_{2}\right) / 2}$

Equation 46 is a straightforward generalization of eq 40 in the most versatile form. According to

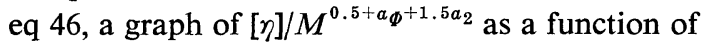
$M^{\left(1-3 a_{2}\right) / 2}$ (Kamide-Miyazaki (KM) plot) should be linear, having $6^{3 / 2} K_{\Phi} K_{0}{ }^{3 / 2}$ (accordingly, $K_{0}$ ) as the intercept. Equation 5 can be rewritten as follows

$$
a=0.5+a_{\Phi}+a_{1}+1.5 a_{2}
$$

where 
Table I. The draining parameter $X$ and the unperturbed chain dimensions $A$ for some typical vinyl-type polymers

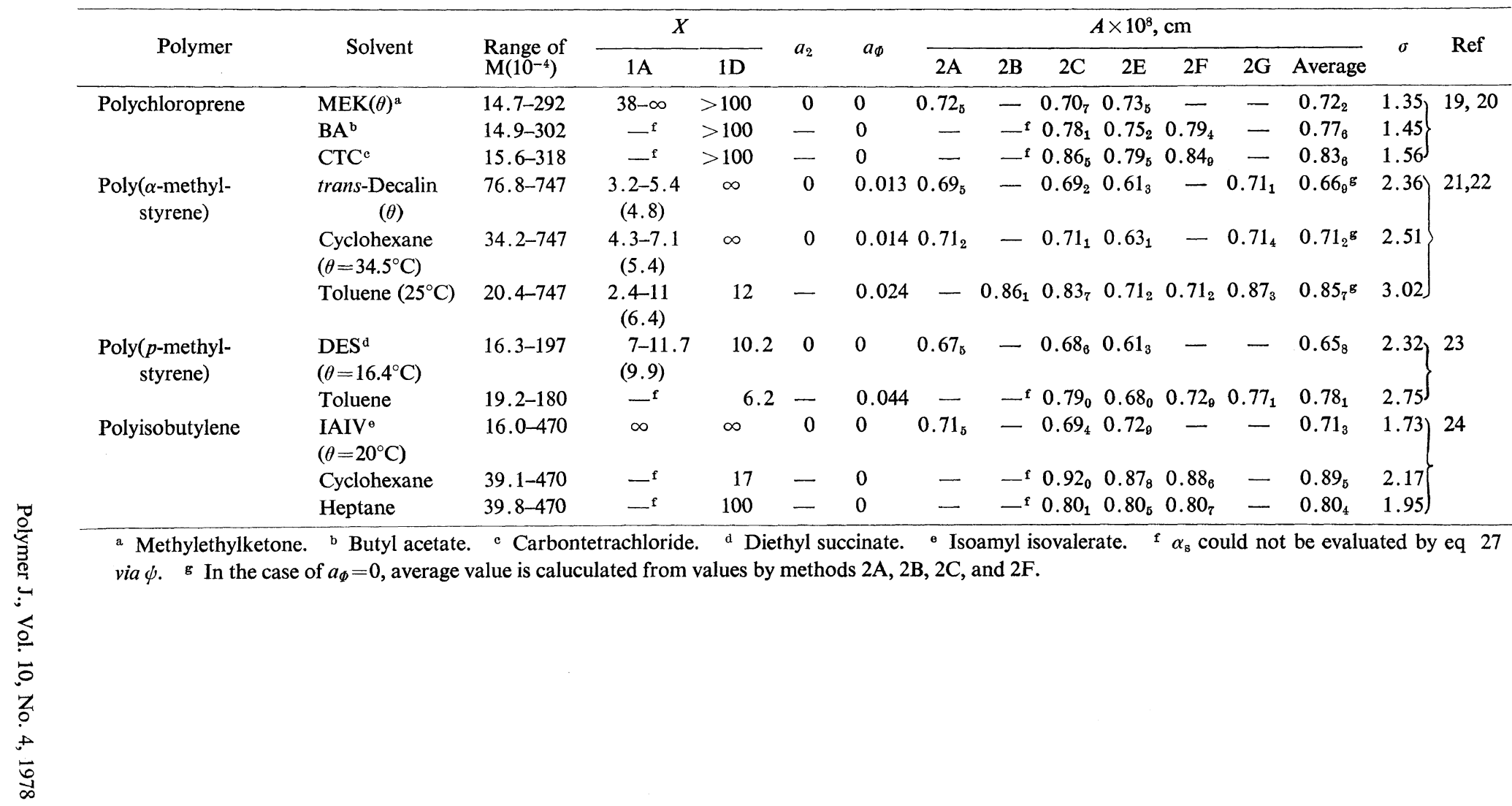




$$
a_{1}=3 \varepsilon
$$

Thus, the value of $a_{1}$ can be roughly estimated from $a, a_{\Phi}$ and $a_{2}$ through use of eq $5^{\prime}$.

These methods for estimating the draining effect and the unperturbed chain dimensions were applied beforehand to some typical vinyl-type polymers in order to test their validity. The literature data $^{19-24}$ employed here are known to be accurate enough to judge the applicability of various theories of the excluded volume effect in detail. The results are summarized in Table $I$. It is evident that for vinyl-type polymers, $X$ exceeds by about five. It should be noted here that the accuracy of $X$ becomes rapidly low in the range $X>10$ due to the incompleteness of the theory on $\Phi$. In this paper, we choose $2.87 \times 10^{2325,26}$ for $\Phi_{0}(\infty)$, but other values such as $2.84 \times 10^{2327}, 2.82 \times 10^{2328}$, and $2.66 \times 10^{2329}$ have also been obtained theoretically. The polymer chain of polychloroprene and polyisobutene can be, in general, treated as impermeable to solvent molecules. But, for poly ( $\alpha$-methylstyrene) and poly ( $p$-methylstyrene) the contribution of the draining effect to $[\eta]$ probably is significant, although very small. This corresponds well to the fact of $a_{\Phi} \neq 0$ for these polymers. For poly ( $\alpha$-methylstyrene), Noda et al. ${ }^{22}$ pointed out that $\alpha_{\eta}\left(\equiv\left([\eta] /[\eta]_{\theta}\right)^{1 / 3},[\eta]_{\theta}\right.$ is $[\eta]$ in a $\theta$ solvent) can not be expressed as a unique function of $z$ and the non-unique dependence of $\alpha_{\eta}$ on $z$ may be attributed to the partial draining of solvent through the polymer coils, but this may not be the only reason. Method $2 \mathrm{G}$ was applied to the data on $\operatorname{poly}(\alpha$-methylstyrene) and poly ( $p$-methylstyrene), for which $a_{\Phi}$ is positive. A much better agreement between $A$ values evaluated by method $2 \mathrm{G}$ and method $2 \mathrm{~A}, 2 \mathrm{~B}$, and $2 \mathrm{C}$ is observed. $\quad a_{2}=0$ and $a_{\Phi}=0$ for polychloroprene and polyisobutylene were experimentally confirmed. In this case, method $2 \mathrm{D}$ is equal to method $2 \mathrm{C}$, and method $2 \mathrm{G}$ reduces to method $2 \mathrm{E}$. In good solvents where $\phi$ exceeds 0.2 , we could not determine $\alpha_{\mathrm{s}}$ from eq 27 because the theoretical limiting value of $\phi$ is $1 / 5.047$. Thus, method 2B is limited in its applicability to the small $\alpha_{\mathrm{s}}$ region. This is the case for cellulose and its derivatives (see, Table III). The results indicate that no large difference exists between the five methods and all these methods yield an $A$ value identical within \pm 0.025 . This proves the validity of these methods.
Methods 2A, 2C, and 2G give the same $A$ value, which is slightly larger than that by method 2E (by about 0.05 ) and method $2 \mathrm{~F}$ (by about 0.03 ). It is noteworthy that, if the comparison is limited to the case of $a_{\Phi}=0$, the difference in the $A$ value determined by methods $2 \mathrm{C}$ and $2 \mathrm{E}$ decreases greatly, being $\sim 0.01$.

\section{RESULTS}

The viscosity, sedimentation, diffusion and light scattering data of various cellulose and amylose derivatives were analyzed according to the methods described above. The polymers are cellulose trinitrate $(\mathrm{CTN})$, cellulose nitrate $(\mathrm{CN})$, cellulose acetate (CA), cellulose tricaproate (CTCp), cellulose tricarbanilate (CTC), methyl cellulose (MC), ethyl cellulose (EC), sodium carboxymethyl cellulose (NaCMC), hydroxyethyl cellulose (HEC), ethylhydroxyethyl cellulose (EHEC), sodium cellulose xanthate $(\mathrm{NaCX})$, amylose, amylose triacetate (ATA), and amylose tricarbanilate (ATC). Tables IIa and IIb summarize the $X$ values thus estimated. In method $1 \mathrm{~A}$ the range of $X$ value and its average value are shown. The figure in parenthesis is the average. In method $1 \mathrm{~B}-1 \mathrm{D}, X$ is calculated by assuming $a_{2}=0$ at first and then $X$ is re-calculated by using $a_{2}$ value in Table III and shown in branket. It is obvious that the effect of $a_{2}$ on an estimated value of $X$ is very small. When $2.66 \times 10^{23}$ is employed as $\Phi_{0}(\infty)$ in place of $2.87 \times 10^{23}$, the $X$ value thus obtained is at most only $8 \%$ larger than that shown in the tables. Table III has the sample number, the breadth in molecular weight distribution of the samples $\left(M_{w} / M_{n}\right)$, linear expansion factor $\alpha_{\mathrm{s}}$ estimated from $\psi$, the parameter $K_{\mathrm{m}}, a$ and $M_{0}$.

The average values of $A$ obtained by methods $2 \mathrm{~A}$ and $2 \mathrm{~B}$ are recorded in the fifth and six columns of Tables IV respectively. Figure 1 represents the Baumann plot constructed according to eq 32 . The values of $A$ determined from the intercepts of the plots are tabulated in the seventh column of Table IV. The Baumann plot can be represented by a straight line for each polymer-solvent system. But the slope of the plot is very often negative, showing that the $B$ value is negative (i.e., among 23 polymer-solvent systems, 15 systems have negative $B, 4$ systems have $B=0$ ). 
Table IIa. The draining parameter $X$ evaluated for cellulose, amylose and their derivatives

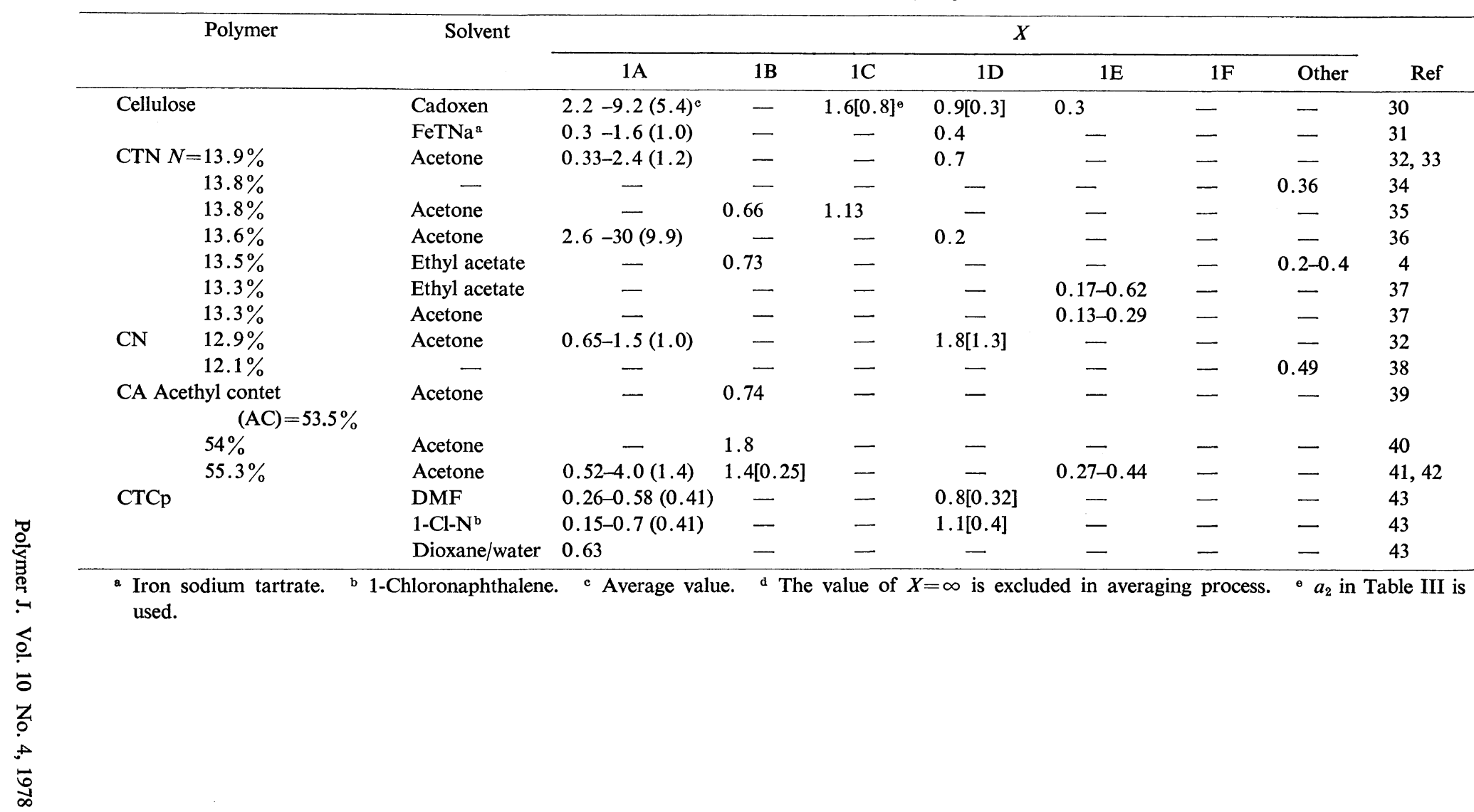


Table IIb. The draining parameter $X$ evaluated for cellulose, amylose and their derivatives

\begin{tabular}{|c|c|c|c|c|c|c|c|c|c|c|}
\hline \multicolumn{2}{|c|}{ Polymer } & \multirow[t]{2}{*}{ Solvent } & \multicolumn{7}{|c|}{$x$} & \multirow[b]{2}{*}{ Ref } \\
\hline & & & $1 \mathrm{~A}$ & 1B & $1 \mathrm{C}$ & 1D & $1 \mathrm{E}$ & $1 \mathrm{~F}$ & Others & \\
\hline \multirow{3}{*}{\multicolumn{2}{|c|}{ CTC }} & Acetone & $0.4-1.8(1.1)$ & - & - & 0.9 & - & - & - & 44,45 \\
\hline & & Cyclohexanone & $0.54-1.6(0.95)$ & - & - & 4.0 & - & - & - & 44,45 \\
\hline & & Dioxane & $0.3-1.6(0.77)$ & - & - & - & - & - & - & 44,45 \\
\hline $\mathrm{MC}$ & $\mathrm{DS}=2$ & Water & $0.3-0.8(0.56)$ & - & - & $0.8[0.19]$ & $0.6-2.7(1.4)$ & 0.21 & - & 46 \\
\hline \multirow[t]{2}{*}{ EC } & & Acetone & - & 2.5 & 2.0 & - & $0.09-1.3(0.5)$ & - & - & 47 \\
\hline & & Acetone & - & 1.1 & 1.1 & - & - & - & - & 48 \\
\hline $\mathrm{NaCMC}$ & $\mathrm{DS}=0.88$ & $\mathrm{NaCl}(\mathrm{I} \rightarrow \infty)$ & $4.3-\infty(8.1)^{\mathrm{d}}$ & $0.2[0.3]$ & - & 2.6 & - & 2.1 & - & 49 \\
\hline \multirow[t]{2}{*}{ HEC } & $\mathrm{DS}=1$ & Water & $0.37-3.6(1.9)$ & - & - & - & - & - & - & 50,51 \\
\hline & & Cadoxen & $0.49-4.2(2.9)$ & - & - & 0.13 & - & - & - & 50,51 \\
\hline EHEC & $\mathrm{DS}=2$ & Water & $0.48-4.3(2.0)$ & $0.12[0.3]$ & 0.1 & - & - & - & 一 & 52 \\
\hline $\mathrm{NaCX}$ & $\mathrm{DS}=0.78$ & $1-M \mathrm{NaOH}$ & $0.1-0.18(0.14)$ & 0.03 & 0.39 & 0.01 & $0.31-\infty$ & - & - & 53 \\
\hline Amylose & & DMSO & $0.17-7.2(1.8)$ & - & - & 0.01 & - & - & - & 54 \\
\hline ATA & & Nitromethane & $0.19-6.4(2.1)$ & - & - & 0.1 & - & - & - & 55 \\
\hline \multirow[t]{2}{*}{ ATC } & & Pyridine/water & $0.9-1.5(1.1)$ & 0.36 & - & 6.0 & - & - & - & 56 \\
\hline & & Pyridine & $0.23-0.66(0.5)$ & 0.70 & - & 5.0 & - & - & - & 57 \\
\hline
\end{tabular}


Table III. Various parameters employed for the evaluation of unperturbed chain dimensions of cellulose, amylose and their derivatives

\begin{tabular}{|c|c|c|c|c|c|c|c|c|c|c|c|c|c|c|}
\hline \multirow{2}{*}{\multicolumn{2}{|c|}{ Polymer }} & \multirow[t]{2}{*}{ Solvent } & \multirow{2}{*}{$\begin{array}{c}\text { Sample } \\
\text { No. }\end{array}$} & \multirow[t]{2}{*}{$M_{w} / M_{n}$} & \multirow[t]{2}{*}{$\alpha_{\mathrm{s}}$} & \multirow[t]{2}{*}{$a_{2}$} & \multirow[t]{2}{*}{$K_{\mathrm{m}}$} & \multirow[t]{2}{*}{$a$} & \multirow{2}{*}{$\begin{array}{l}M_{0} \\
\times 10^{-5} \\
\end{array}$} & \multirow{2}{*}{$\begin{array}{l}K_{\Phi} \\
\times 10^{20} \\
\end{array}$} & \multirow[t]{2}{*}{$a_{\Phi}$} & \multicolumn{2}{|c|}{$a_{1}$} & \multirow[t]{2}{*}{ Ref } \\
\hline & & & & & & & & & & & & eq 18 & eq 5 & \\
\hline \multirow{2}{*}{\multicolumn{2}{|c|}{ Cellulose }} & Cadoxen & 6 & $1.8-2.3$ & $1.1-1.2$ & -0.216 & 0.0264 & $0.79_{2}$ & 4.61 & 4.55 & 0.304 & 0.22 & 0.31 & 30 \\
\hline & & $\mathrm{FeTNa}$ & 9 & 2.0 & $1.0-1.2$ & -0.296 & 0.0494 & $0.77_{9}$ & 2.01 & 5.01 & 0.429 & 0.17 & 0.29 & 31 \\
\hline \multirow{2}{*}{\multicolumn{2}{|c|}{$\begin{array}{r}\text { CTN } N=13.9 \% \\
13.6 \%\end{array}$}} & Acetone & 6 & 1.2 & $1.0-1.2$ & 0 & 0.0076 & $0.90_{3}$ & 5.58 & 6.36 & 0.379 & 0.05 & $<0.01$ & 32,33 \\
\hline & & Acetone & 9 & 2.0 & $1.0-1.1$ & 0 & 0.0047 & $0.93_{2}$ & 1.27 & 5.72 & 0.424 & 0 & $<0.01$ & 36 \\
\hline $\mathrm{CN}$ & $12.9 \%$ & Acetone & 4 & 1.2 & $1.1-1.3$ & -0.024 & 0.0048 & $0.91_{6}$ & 1.55 & 29 & 0.274 & 0.18 & 0.21 & 32,33 \\
\hline \multirow{2}{*}{\multicolumn{2}{|c|}{$\mathrm{CA} \quad \mathrm{AC}=55.3 \%$}} & Acetone & 9 & 1.29 & $1.0-1.1$ & -0.471 & 0.133 & $0.61_{6}$ & 0.56 & 0.226 & 0.716 & 0.13 & 0.11 & 41 \\
\hline & & THF & 6 & 1.29 & $1.0-1.2$ & 0 & 0.0513 & $0.68_{8}$ & 0.56 & 573 & 0.105 & 0.150 & 0.08 & 41 \\
\hline \multirow{3}{*}{\multicolumn{2}{|c|}{ CTCp }} & DMF & 4 & $1.03-1.5$ & 1.0 & -0.248 & 0.268 & $0.49_{5}$ & 2.86 & 4.17 & 0.377 & 0.01 & -0.01 & 43 \\
\hline & & $1-\mathrm{Cl}-\mathrm{N}$ & 4 & $1.03-1.5$ & $1.0-1.1$ & -0.248 & 0.159 & $0.51_{5}$ & 2.86 & 4.17 & 0.377 & 0.01 & 0.01 & 43 \\
\hline & & Dioxane/water & 4 & $1.03-1.5$ & $1.0-1.1$ & -0.248 & 0.274 & $0.48_{3}$ & 2.86 & 4.17 & 0.377 & 0.01 & -0.02 & 43 \\
\hline \multirow{5}{*}{\multicolumn{2}{|c|}{ СТC }} & Anisol & 4 & $1.76-2.3$ & 1.0 & 0 & 0.095 & $0.52_{4}$ & 8.26 & - & 一 & 0 & - & 58 \\
\hline & & Cyclohexanol & 3 & $2.0-2.3$ & 1.0 & 0 & - & 一 & - & - & - & 0 & - & 58 \\
\hline & & Acetone & 6 & $1.76-2.4$ & $1.01-1.04$ & 0 & 0.0012 & $0.91_{2}$ & 8.26 & 60.6 & 0.21 & 0.09 & 0.20 & 44,59 \\
\hline & & Cyclohexnone & 5 & $1.76-2.4$ & $1.02-1.05$ & 0 & 0.0026 & $0.83_{7}$ & 8.26 & 0.75 & 0.508 & -0.10 & 0.13 & 44,59 \\
\hline & & Dioxane & 4 & $1.76-2.4$ & $1.01-1.03$ & 0 & 0.00082 & $0.97_{1}$ & 8.26 & 1.52 & 0.462 & -0.11 & $<0.01$ & 44,59 \\
\hline $\mathrm{MC}$ & $\mathrm{DS}=2$ & Water & 5 & $2.4-2.9$ & $1.01-1.04$ & -0.280 & 0.473 & $0.50_{8}$ & 2.64 & 2.01 & 0.464 & 0.008 & -0.09 & 46 \\
\hline $\mathrm{NaCMC}$ & $\mathrm{DS}=0.88$ & $\mathrm{NaCl}(\mathrm{I} \rightarrow \infty)$ & 4 & $2.1-3.7$ & $1.0-$ & -0.072 & 0.173 & $0.60_{4}$ & 3.95 & 1880 & 0.192 & 0.022 & 0.02 & 49 \\
\hline HEC & $\mathrm{DS}=1$ & Water & 5 & $1.5-1.7$ & $1.02-1.04$ & -0.128 & 0.0074 & $0.89_{0}$ & 2.23 & 0.54 & 0.608 & -0.004 & -0.03 & 51 \\
\hline EHEC & $\mathrm{DS}=2$ & Water & 4 & $3.07-3.23$ & $1.01-1.10$ & -0.256 & 0.0406 & $0.75_{4}$ & 3.02 & 0.207 & 0.688 & 0.08 & -0.05 & 52 \\
\hline $\mathrm{NaCX}$ & $\mathrm{DS}=0.78$ & $1-M \mathrm{NaOH}$ & 3 & 1.25 & $1.00-1.01$ & -0.240 & 0.0477 & $0.67_{8}$ & 4.18 & 0.088 & 0.568 & 0.01 & -0.10 & 53,60 \\
\hline \multicolumn{2}{|c|}{ Amylose } & DMSO & 9 & 1.5 & $1.07-1.17$ & -0.336 & 0.0013 & $0.86_{8}$ & 8.19 & 0.018 & 0.794 & 0.05 & 0.08 & 54 \\
\hline \multicolumn{2}{|l|}{ ATA } & Nitrometane & 12 & 1.5 & $1.04-1.33$ & 0 & 0.0012 & $0.86_{2}$ & 7.53 & 6.75 & 0.379 & -0.10 & -0.02 & 55 \\
\hline \multirow{2}{*}{\multicolumn{2}{|c|}{ ATC }} & Pyridene/water & 9 & 1.5 & 1.0 & 0 & 0.0039 & $0.59_{8}$ & 11.8 & 218 & 0.144 & -0.012 & -0.015 & 56 \\
\hline & & Pyridine & 9 & 1.5 & $1.02-1.29$ & 0 & 0.0012 & $0.86_{4}$ & 8.55 & 35.7 & 0.056 & 0.13 & 0.31 & 57,61 \\
\hline
\end{tabular}


Unperturbed Dimensions of Cellulose Derivatives

Table IV. Unperturbed chain dimensions $K_{0}$ and $A$ of cellulose, amylose and their derivatives

\begin{tabular}{|c|c|c|c|c|c|c|c|c|c|c|c|c|}
\hline \multirow{2}{*}{\multicolumn{2}{|c|}{ Polymer }} & \multirow{2}{*}{\multicolumn{2}{|c|}{ Solvent }} & \multicolumn{2}{|c|}{$K_{0} \times 10^{16}, \mathrm{~cm}^{2}$} & \multicolumn{7}{|c|}{$A \times 10^{8}, \mathrm{~cm}$} \\
\hline & & & & $2 \mathrm{D}$ & $2 \mathrm{G}$ & $2 \mathrm{~A}$ & 2B & $2 \mathrm{C}$ & $2 \mathrm{D}^{\mathrm{a}}$ & $2 \mathrm{E}$ & $2 \mathrm{~F}$ & $2 \mathrm{G}^{\mathrm{a}}$ \\
\hline \multirow{2}{*}{\multicolumn{2}{|c|}{ Cellulose }} & \multicolumn{2}{|c|}{ Cadoxen } & - & $0.54_{8}$ & - & 1.53 & 1.83 & 1.92 & 1.21 & 1.20 & 1.57 \\
\hline & & \multicolumn{2}{|c|}{$\mathrm{FeTNa}$} & 28.2 & 23.7 & - & 2.81 & 2.31 & 2.27 & 1.31 & 1.29 & 2.17 \\
\hline \multicolumn{13}{|c|}{ CTN } \\
\hline \multirow{2}{*}{\multicolumn{2}{|c|}{$\begin{array}{c}N=13.9 \% \\
13.6 \%\end{array}$}} & \multicolumn{2}{|c|}{ Acetone } & 一 & 1.00 & - & 2.41 & 2.43 & $(2.43)^{\mathrm{b}}$ & $0.79_{2}$ & 1.02 & 2.45 \\
\hline & & \multicolumn{2}{|c|}{ Acetone } & 一 & 4.38 & - & 2.04 & 2.10 & $(2.10)$ & $0.97_{5}$ & $0.99_{4}$ & 2.09 \\
\hline $\mathrm{CN} \quad 12$ & $2.9 \%$ & \multirow{2}{*}{\multicolumn{2}{|c|}{ Acetone }} & 0.75 & 0.80 & 一 & 1.84 & 1.84 & 1.85 & $0.52_{1}$ & $0.73_{\theta}$ & 1.91 \\
\hline \multicolumn{12}{|c|}{ CA } & \\
\hline \multicolumn{2}{|c|}{$\mathrm{AC}=55.3 \%$} & \multicolumn{2}{|c|}{ Acetone } & 18 & 16 & - & 1.68 & 2.14 & 1.77 & 1.10 & 1.12 & 1.75 \\
\hline \multirow{4}{*}{\multicolumn{2}{|c|}{ CTCp }} & \multicolumn{2}{|c|}{ DMF } & 65.4 & 75.8 & 1.80 & - & 2.14 & 1.94 & $0.96_{1}$ & $0.92_{0}$ & 1.99 \\
\hline & & \multirow{2}{*}{\multicolumn{2}{|c|}{$\begin{array}{l}1-\mathrm{Cl}-\mathrm{N} \\
\text { dioxane }\end{array}$}} & 65.4 & 62.8 & - & 1.75 & 2.14 & 1.94 & $0.89_{5}$ & $0.85_{3}$ & 1.82 \\
\hline & & & & 65.4 & 71.3 & - & - & - & - & $0.92_{9}$ & $0.95_{6}$ & 1.90 \\
\hline & & \multicolumn{4}{|c|}{ /water } & & & & & & & \\
\hline \multirow{5}{*}{\multicolumn{2}{|c|}{ CTC }} & \multicolumn{2}{|c|}{ Anisol } & 一 & - & $0.81_{8}$ & 一 & - & 一 & $0.77_{4}$ & $0.75_{8}$ & - \\
\hline & & \multicolumn{2}{|c|}{ Cyclohexanol } & - & - & $0.84_{1}$ & - & - & 一 & - & - & - \\
\hline & & \multicolumn{2}{|c|}{ Acetone } & - & 0.26 & - & 1.43 & 1.43 & $(1.43)$ & $0.55_{7}$ & $0.56_{0}$ & 1.25 \\
\hline & & \multicolumn{2}{|c|}{ Cyclohexanone } & - & 0.26 & - & 1.36 & 1.43 & $(1.43)$ & $0.66_{8}$ & $0.67_{1}$ & 1.25 \\
\hline & & \multicolumn{2}{|c|}{ Dioxane } & 一 & $0.55_{\theta}$ & - & 1.88 & 1.85 & $(1.85)$ & $0.54_{8}$ & $0.46_{7}$ & 1.83 \\
\hline $\mathrm{MC}$ & \multicolumn{2}{|c|}{$\mathrm{DS}=2^{\mathrm{c}}$} & \multirow{2}{*}{$\begin{array}{l}\text { Water } \\
\mathrm{NaCl}(\mathbf{I} \rightarrow \infty)\end{array}$} & 23.0 & 22.4 & - & 2.05 & 2.56 & 2.34 & 1.23 & 1.25 & 2.31 \\
\hline $\mathrm{NaCMC}$ & $\mathrm{DS}=0$ & & & 0.83 & 0.79 & - & 1.42 & 1.50 & 1.47 & 1.26 & 1.25 & 1.44 \\
\hline HEC & $\mathrm{DS}=1$ & & Water & 3.69 & 3.71 & - & 2.10 & 2.40 & 2.25 & $0.93_{0}$ & $0.95_{7}$ & 2.26 \\
\hline EHEC & $\mathrm{DS}=2$ & & Water & 17.8 & 17.1 & - & 2.1 & 2.41 & 2.37 & 1.24 & 1.22 & 2.32 \\
\hline $\mathrm{NaCX}$ & $\mathrm{DS}=0$ & & $1-M \mathrm{NaOH}$ & 39.4 & 41.4 & - & 3.30 & 4.04 & 3.86 & 1.03 & 1.03 & 3.96 \\
\hline Amylose & & & DMSO & 20.9 & 24.7 & - & 1.48 & 1.33 & 1.62 & $0.60_{2}$ & $0.56_{1}$ & 1.76 \\
\hline ATA & & & Nitrometane & - & $0.21_{4}$ & - & 1.04 & 1.14 & $(1.14)^{\mathrm{b}}$ & $0.55_{4}$ & $0.55_{0}$ & 1.06 \\
\hline ATC & & & $\begin{array}{l}\text { Pyridine } \\
\text { /Water }\end{array}$ & - & $0.16_{3}$ & $0.99_{8}$ & 一 & $0.99_{8}$ & $\left(0.99_{8}\right)$ & $0.77_{5}$ & $0.77_{0}$ & 0.99 \\
\hline & & & Pyridine & - & $0.16_{8}$ & - & 1.14 & 1.08 & $(1.08)$ & $0.56_{5}$ & 0.70 & 1.00 \\
\hline
\end{tabular}

a the value at $M_{w}=1 \times 10^{5}$ is shown.

$\mathrm{b}$ in this case $a_{2}=0$, then the value by $2 \mathrm{D}$ concides with that by $2 \mathrm{C}$.

c $\mathrm{DS}=$ degree of substitution.

This contrast sharply with the positive value of $A_{2}$ for these polymer-solvent systems. The result that $B<0$ arises from the non-gaussian nature of a polymer chain in unperturbed state as shown immediately later. In Figure 2 the molecular weight dependence of $\left\langle S^{2}\right\rangle_{0, w} / M_{w}$, estimated by method $2 \mathrm{~A}$ and or $2 \mathrm{~B}$, is demonstrated. Figure 2 shows that $a_{2}$ in eq 7 can be empirically regarded as constant in the molecular weight range concerned. The $a_{2}$ values obtained thus are given in the sixth column of Table III. It is of interest to note that $a_{2}$ values for cellulose, amylose and their derivatives in solution are zero or negative. In the case of $a_{2} \neq 0$, the Baumann plot is not, strictly speaking, applicable. Thus, in this case, the experimental data are plotted according to eq
33 (BKM plot) in Figures $3 a$ and $3 b$. It is particularly noteworthy in this figure that the BKM plot can be approximated with a very good straight line having a positive slope. The $K_{0}$ value estimated from the intercept at $M_{w}^{\left(1-3 a_{2}\right) / 2} \rightarrow 0$ are shown in the third column of Table IV. The $A$ values for $M_{w}=1 \times 10^{5}$ calculated from $K_{0}$ by eq 34 are also included in the same table.

The viscosity data are plotted according to eq 40 (SF plot). As illustrated in Figure 4, the SF plot apparently gives a good straight line and $A$ can be evaluated from its extrapolation to $M_{w}^{\prime \prime 2}=0$ (method 2E). The results are tabulated in the ninth column of Table IV. However, as was noted in the theoretical section, eq 40 was based on the assumption that $a_{2}=0, a_{\Phi}=0$ and $a<a^{*}$ 


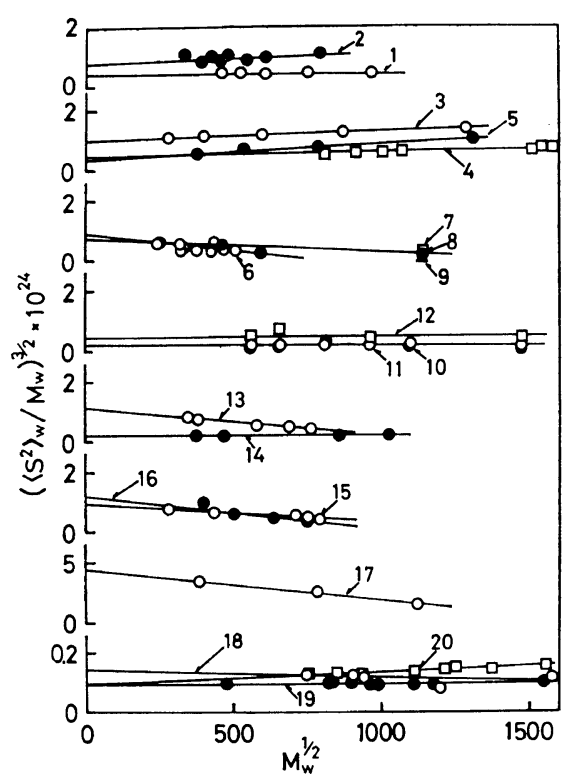

Figure 1. Baumann plot (eq 32): 1, cellulose in cado$\operatorname{xen}^{30} ; 2$, cellulose in FeTNa ${ }^{31} ; 3, \mathrm{CTN}(N=13.9 \%)$ in acetone ${ }^{32} ; 4, \mathrm{CTN}(N=13.6 \%)$ in acetone ${ }^{36} ; 5, \mathrm{CN}$ $(N=12.9 \%)$ in acetone ${ }^{32} ; 6, \mathrm{CA}$ (acetyl content $\left.55.3 \%\right)$ in acetone ${ }^{41} ; 7, \mathrm{CTCp}$ in $\mathrm{DMF}^{43} ; 8, \mathrm{CTCp}$ in $1-\mathrm{Cl}-$ $\mathrm{N}^{43} ; 9$, CTCp in dioxane/water ${ }^{43} ; 10$, CTC in acetone $^{44} ; 11$, CTC in cyclohexanone ${ }^{44} ; 12$, CTC in dioxane $^{44} ; 13, \mathrm{MC}$ in water ${ }^{46} ; 14, \mathrm{NaCMC}$ in aq. $\mathrm{NaCl}^{49} ; 15, \mathrm{HEC}$ in water ${ }^{51} ; 16$, EHEC in water ${ }^{52}$; $17, \mathrm{NaCX}$ in $1-M \mathrm{NaOH}^{53,60} ; 18$, amylose in $\mathrm{DMSO}^{54}$; 19 , ATA in nitromethane ${ }^{55} ; 20$, ATC in pyridine. ${ }^{61}$ are realized concurrently, where $a^{*}$ is the upper applicable limit $a .^{62}$ Figure 5 depicts the results of the $\log$ - $\log$ plot of $\Phi$ and $M_{w}$. As can be seen from the figure, $\Phi$ for cellulose, amylose and their derivatives is strongly molecular weight dependent and can be empirically expressed by eq 44 , to a fairly good approximation, over the entire experimentally accessible molecular weight range. $a_{\Phi}$ was determined in this manner from the slope of the plot in Figure 5 and summarized in the eleventh column of Table III. The fact of $a_{2} \leq 0$ and $a_{\Phi}>0$ for the almost cellulose, amylose and their derivatives indicate that eq $\mathbf{4 0}$ is apparently inadequate for these polymers as noted previously. Up to now data for these polymers have been widely analyzed according to eq 40 without reference to $a_{2}$ and $a_{\Phi}$. The result $a_{\Phi}>0$ that is compatible with $X$ value $\lesssim 2$ as shown in Table III.

By using the parameters $K_{\mathrm{m}}, a$ and $M_{0}$ in Table III, the Flory's $K$ value, accordingly $A$, was calculated from eq 43 . The results are shown in the tenth column of Table IV (method 2F).

Figures $6 \mathrm{a}$ and $6 \mathrm{~b}$ show the data graphed according to eq 46 (the Kamide-Miyazaki (KM) plot) for the same viscosity data as those in Fig. 4. The plots are quite linear over the range examined and present no great problem in extrapolation. The $K_{0}$ values determined from the intercept are assembled in the fourth column of Table IV (method 2G) and the $A$ values for $M_{w}=1 \times 10^{5}$ are shown in the same table.

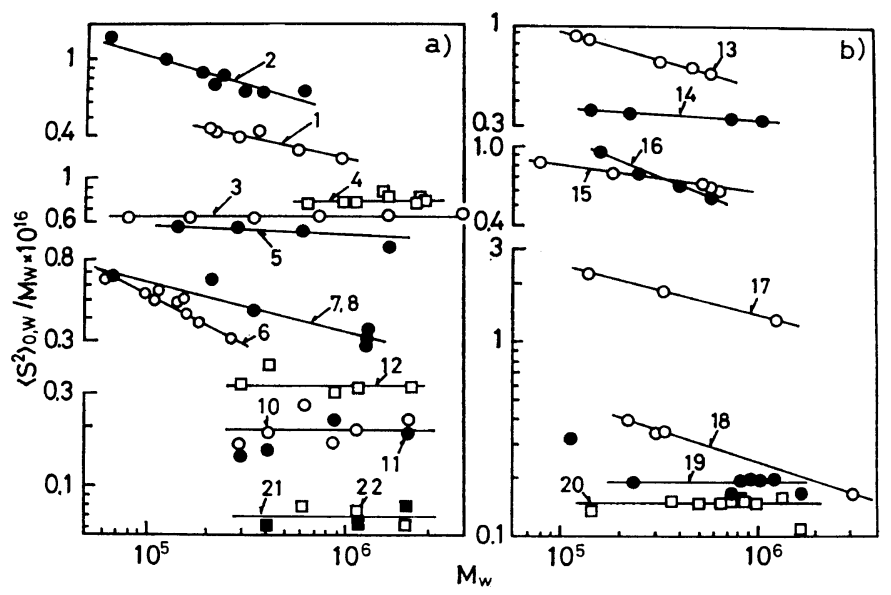

Figure 2. The molecular weight dependence of $\left\langle S^{2}\right\rangle_{0, w} / M_{w}$. Numbers 1-20 on lines have the same meanings as those in Figure $1 ; 21$, CTC in anisol ${ }^{44,58} ; 22$, CTC in cyclohexanol. ${ }^{44,59}$ 


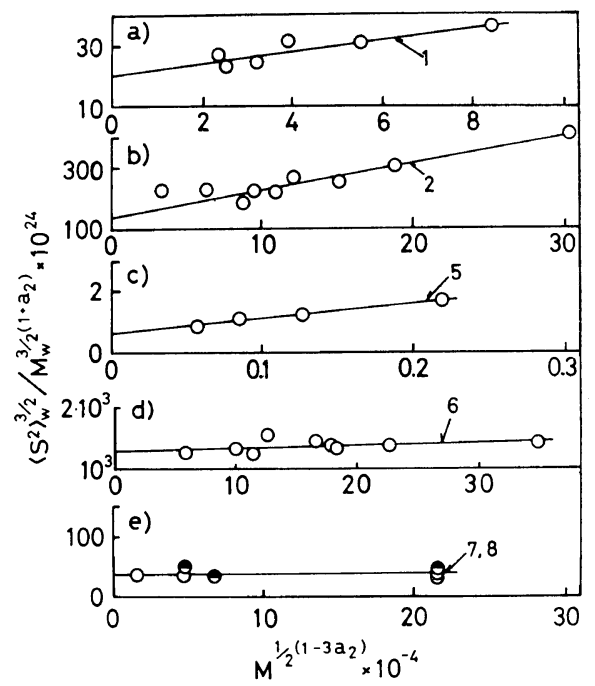

(a)

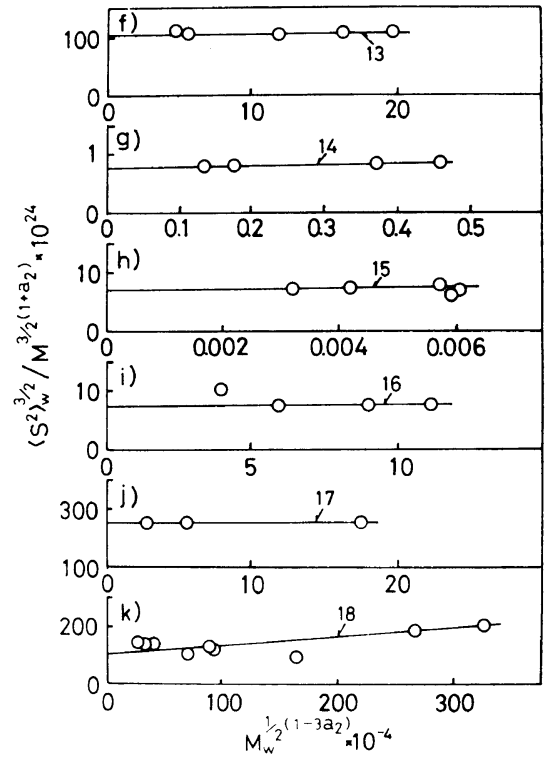

(b)

Figure 3. Baumann-Kamide-Miyazaki (BKM) plot (eq 33). Numbers on lines have the same meanings as those in Figure 1.

\section{DISCUSSION}

The considerable difficulty in determining $X$ by method $1 \mathrm{~A}$ lies in the fact that the samples used in the literature had wide molecular weight distributions (MWD) and their accurate shape was not determined experimentally as shown in Table III.

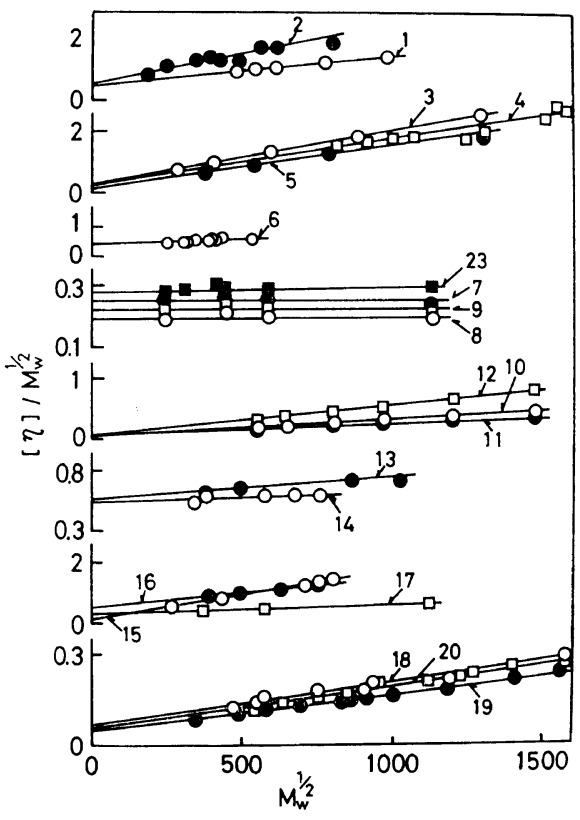

Figure 4. Stockmayer-Fixman plot (eq 40). Numbers 1-20 on lines have the same meanings as those in Figure $1 ; 23$, CTCp in dioxane. ${ }^{43}$

This is a weak point in method 1A. Exceptional cases are $\mathrm{CN}^{32,33} \mathrm{CTN}^{32,33}$ and $\mathrm{CA}^{41}$ whose samples have relatively narrow MWD $\left(M_{w} / M_{n} \simeq 1.2\right)$. Even in these cases, the $X$ values estimated by using method $1 \mathrm{~A}$ are less than two for the most part. Actually, the magnitude of $X$ value obtained by using various methods for each polymer sample is susceptible to large error. An accumulation of knowledge of $X$ values is necessary in order to obtain the definite conclusions on the draining effect. Such a compilation of $X$ values is shown in Tables IIa and IIb. Considering the experimental accuracy, we cannot evaluate the exact value of $X$, but different methods always give $X \lesssim 2$ with some exceptions, and this is considerably lower than that of usual vinyl-type polymers (Table I). In addition, the value of $a$ calculated from $\lambda$ by using eq $15^{\prime}$ is on the average, only $40 \%$ of the experimental one. It is reasonable to consider that the partially free draining effect on $[\eta]$ can never be, more or less, ignorable for cellulose, amylose and their derivatives. This conclusion was already drawn for $\mathrm{CN}$ previously by Kamide. ${ }^{5}$

An attempt was made to check the consistency among the methods utilized for estimating the 


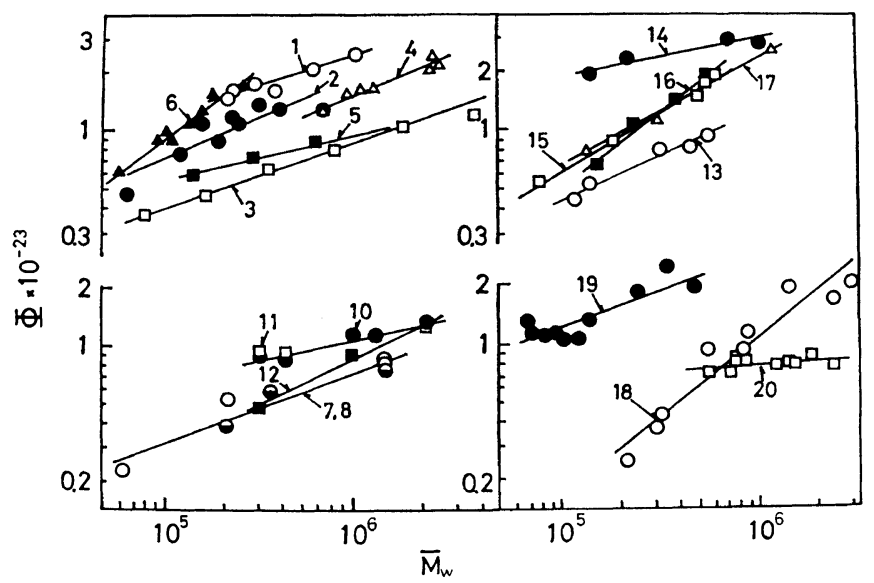

Figure 5. The molecular weight dependence of Flory's viscosity parameter $\Phi$. Numbers on lines have the same meanings as those in Figure 1.

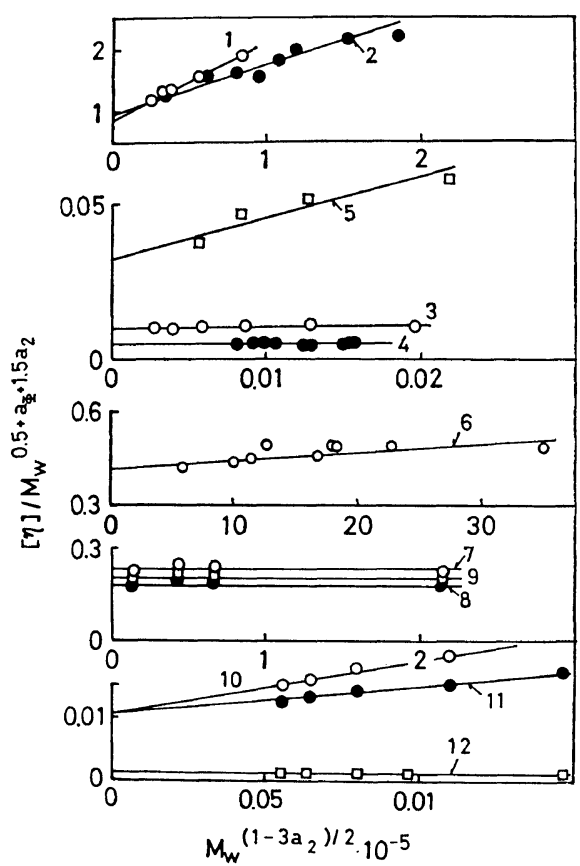

(a)

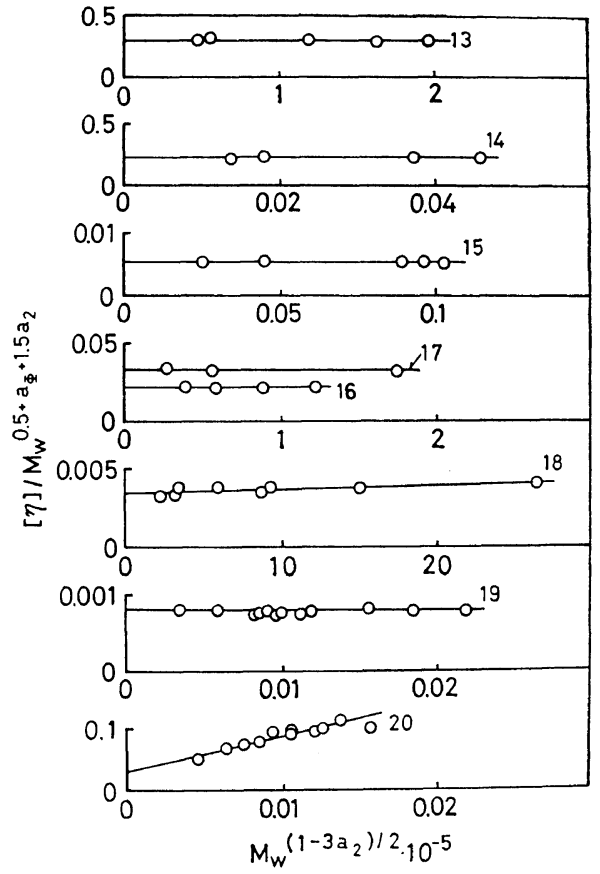

(b)

Figure 6. Kamide-Miyazaki (KM) plot (eq 46). Numbers on lines have the same meanings as those in Figures 1 and 2.

unperturbed chain dimensions. For this purpose, the correlation coefficient $r$ was calculated for any two methods arbitrarily chosen. The results are schematically presented in Figure 7, where $r$ is indicated on the line connecting two methods. When pairs of $A$ values obtained by the two me- thods is less than four, the $r$ value was not calculated due to the high uncertainty of $r$. Although methods $2 \mathrm{~B}, 2 \mathrm{C}$, and $2 \mathrm{D}$ are based on the thermodynamic approach and method $2 \mathrm{G}$ is a hydrodynamic approach, the $A$ values obtained by these methods are very closely correlated with each other. 
(2A)

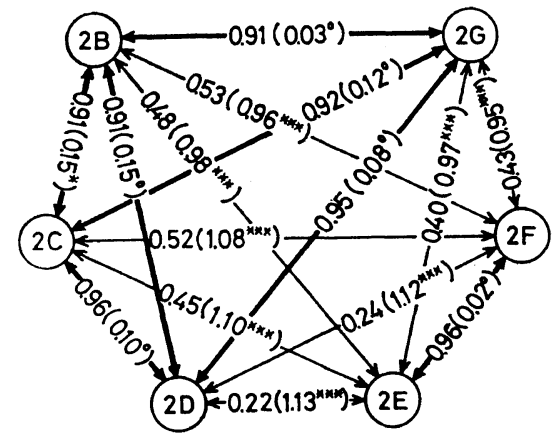

Figure 7. Correlation coefficient $r$ and the average difference of $A$ between the two methods arbitrarily chosen. The average difference of $\boldsymbol{A}$ is given in parenthesis: ${ }^{\circ}$, insignificant (i.e., the difference is below the $5 \%$ level); ${ }^{*}$, questionable significant (i.e., the difference is above the $5 \%$ level); ***, highly significant (i.e., the difference is above the $0.1 \%$ level).

On the other hand, the $A$ value estimated by method $2 \mathrm{E}$ exhibits high correlation with that by method $2 \mathrm{~F}$, as was the case for various vinyltype polymers. ${ }^{18} \quad r$ between $2 \mathrm{D}$ and $2 \mathrm{G}$ is larger than that between $2 \mathrm{C}$ and $2 \mathrm{G}$, as is expected.

A different conclusion should be drawn from the different group of the analytical procedures adopted. Examination of the literature discloses that in the case of using methods $2 \mathrm{~B}$, and $2 \mathrm{C}$, the polymer chain was concluded without exception to be inflexible and with methods $2 \mathrm{E}$ and $2 \mathrm{~F}$, the chain was always regarded as flexible. When methods $2 \mathrm{~B}$ (or $2 \mathrm{C}$ ) and $2 \mathrm{E}$ were applied using the same data, the results obtained by the former method were considered more reliable. Hence, the analytical method utilized is very important and should be carefully examined in advance. The confusion of the concept, in the past, to the flexibility and draining effect of cellulose and its derivatives seems not to be ascribed to the inconsistence of the experimental data, but mainly to the unreasonable usage of the analytical methods.

For cellulose, amylose and their derivatives in solution, $a_{2}$ is zero or negative. This conclusion is not drawn by using erroneously an indirect method for evaluating $\alpha_{s}$, because $a_{2}<0$ was found even in theta solutions (for example, CTCp in $\mathrm{DMF}^{43}$ and $\mathrm{MC}$ in water ${ }^{46}$ ). This is then under- stood as a consequence of an increase in the chain stiffness with a decrease in its length. $a_{2}<0$ can not be explained in terms of the statistics of the pearl-necklace chain model. ${ }^{63}$ Recently, Yamakawa and his coworkers have theoretically demonstrated, on the basis of helical wormlike chain model, that in some case $a_{2}$ becomes negative. ${ }^{64,65}$ The value of $\lambda$, defined by eq 14 , is zero or negative for majority of celluloses. The $A$ values by method 2D, in which $a_{2}<0$ is well taken into account, is in better agreement with $A$ made by method $2 \mathrm{G}$ than that by method $2 \mathrm{C}$. These are additional supports for $a_{2}<0$.

Kurata and Stockmayer described in their excellent review that $\Phi$ should remain essentially constant at its assymptotic value $\Phi_{0}(\infty){ }^{2}$ Their prediction was decidedly shown wrong as is indicated in Figure 5 by the presented analysis of numerous experimental data, which have been published after an appearance of their review. In fact, in cellulose and its derivatives, as described previously, an absolute value of $\Phi$ is not accurate as compared with that of vinyl-type polymers. But, $\Phi$ can never be treated as constant over a wide range of molecular weight assessed. Evidently, $a_{\Phi}$, which is a more rigorous criterion of the draining effect, is always distinctly positive (Table III). This agrees well with the results on the $X$ values in Tables IIa and IIb. In consequence, the experimental findings, $a_{2} \leq 0$ and $a_{\Phi}>0$, undoubtdly prove wrong the theoretical basis (i.e., the "twoparameter" theory) of methods $2 \mathrm{E}$ and $2 \mathrm{~F}$ and the conclusions drawn by using these methods are seriously called into questioned.

Of great experimental significance is the fact that methods $2 \mathrm{~A}, 2 \mathrm{~B}, 2 \mathrm{C}, 2 \mathrm{D}$, and $2 \mathrm{G}$, which are conveniently classified as group $\mathrm{I}$, give almost an identical value of $A$ with an estimated uncertainty of $\pm 7 \%$ (with an exception of the combination of methods $2 \mathrm{~B}$ and $2 \mathrm{C}$ ), which is smaller in magnitude by a factor of about two than that obtained by methods $2 \mathrm{E}$ and $2 \mathrm{~F}$ (group II). As is illustrated in Figure 7, the difference of $A$ value between group I and group II is highly significant at the $0.1-\%$ level. The group II obviously underestimates $A$. An exception is $\mathrm{NaCMC}^{49}$ in which the drainig effect contributes only slightly to $[\eta]$ ( $X \simeq 8.6$ by method $1 A$ and $a_{\Phi}+1.5 a_{2} \simeq 0.08$ ) and the ratio of the values of $A$ by method $2 \mathrm{E}$ to that of $A_{(\mathrm{m})}$ is found to be 0.88 , where $A_{(\mathrm{m})}$ is the most reliable 


\section{K. KAMIDE and Y. MIYAZAKI}

value, as defined later. The $A$ value, directly measured in theta solvents, agrees on occasion with that evaluated by methods $2 \mathrm{~B}, 2 \mathrm{D}$, and $2 \mathrm{G}$ from the data in non-theta solvents (for example, CTCp and ATC). This also provides evidence of the validity of methods $2 \mathrm{~B}, 2 \mathrm{D}$, and $2 \mathrm{G}$.

All the graphical procedures (methods 2C, 2D, $2 \mathrm{E}$, and $2 \mathrm{G}$ ) are roughly linear and even in the large $M_{w}$ range they do not show downward curvature (with exception of $\mathrm{CTN}(N=13.9 \%)$ and $\mathrm{CN}$ ( $N=12.9 \%$ ) in acetone). Hence, the linearity of the plots cannot be taken as a reasonable manifestation of the validity of the procedures. It appears to be true that the neglect of the higher terms of $z$ in eq 28 , is reasonably acceptable. This agrees with $\alpha_{\mathrm{s}} \simeq 1$ and $z \sim 0$.

If $a_{2} \neq 0$, method 2D yields an $A$ value which is higher than that by method $2 \mathrm{C}$ by about $0.1 \times$ $10^{-8} \mathrm{~cm}$ and is only about 3-\% different from that by method $2 \mathrm{G}$. In method $2 \mathrm{D}$ the $A$ value is less sensitive than $B$ (when $B$ is negative) to the $a_{2}$ value employed. The $A$ value, determined by method $2 \mathrm{G}$, depends markedly on $a_{\Phi}+1.5 a_{2}$

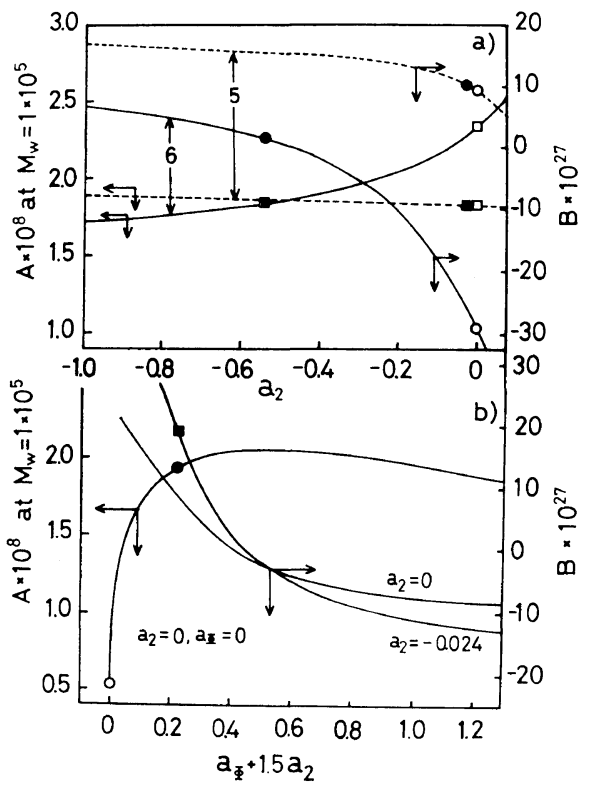

Figure 8. Effect of $a_{2}$ and $a_{\Phi}+1.5 a_{2}$ on the values of $A$ and $B$, estimated by methods $2 \mathrm{D}$ and $2 \mathrm{G}$, respectively, for $\mathrm{CN}(N=12.9 \%)$ in acetone ${ }^{32,33}$ and CA in aceton $\mathrm{e}^{41}$ : open mark, values determined by method 2C $\left(a_{2}=0\right)$ or method 2E $\left(a_{2}=0\right.$ and $\left.a=0_{\phi}\right)$; closed mark, values determined by method $2 \mathrm{D}$ or method $2 \mathrm{G}$, using the experimental data of $a_{2}$ and $a_{\Phi}$. value, especially in the range of $a_{\Phi}<0.1$ and the $B$ value, obtaind by using method $2 \mathrm{G}$, is also highly sensitive to $a_{\Phi}+1.5 a_{2}$. As an illustration, the $A$ and $B$ values were determined for $\mathrm{CN}(N=12.9 \%)$ in acetone and for CA (acetyl content, $55.3 \%$ ) in acetone by using methods $2 \mathrm{D}$ and $2 \mathrm{G}$, assuming $a_{2}$ and $a_{\Phi}$ values. The results are graphed in Figure 8. It should be born in mind that the slope of the BKM, SF, and KM plots for cellulose and amylose derivatives are often too small to allow for an accurate evaluation of $B$.

The $A$ values estimated by methods $2 \mathrm{E}$ and $2 \mathrm{~F}$, $A_{(2 \mathrm{E})}$ and $A_{(2 \mathrm{~F})}$, become smaller as the polymer chain has larger positive $a_{2}$ together with a larger positive $a_{\Phi}$. This is illustrated in Figure 9, where the ratio of $A$ estimated by method $2 \mathrm{E}$ to the most reliable $A$ value (which will be given later) is plotted against $a_{\Phi}+1.5 a_{2}$. It can be expected from Figure 8 that the magnitude of $a_{\Phi}+1.5 a_{2}$ serves as a measure for reliability of methods $2 \mathrm{E}$ and $2 \mathrm{~F}$; that is, the disagreement with the $A$ value by method $2 \mathrm{E}$ or $2 \mathrm{~F}$ and that by other methods is greatest for large value of $a_{\Phi}+1.5 a_{2}$. As already pointed out, the values of $A$ and $B$ obtained by applying method 2E, $2 \mathrm{~F}$ or similar methods, lack reliability, especially at higher $a_{\Phi}+1.5 a_{2}$ value.

A significant improvement in the agreement

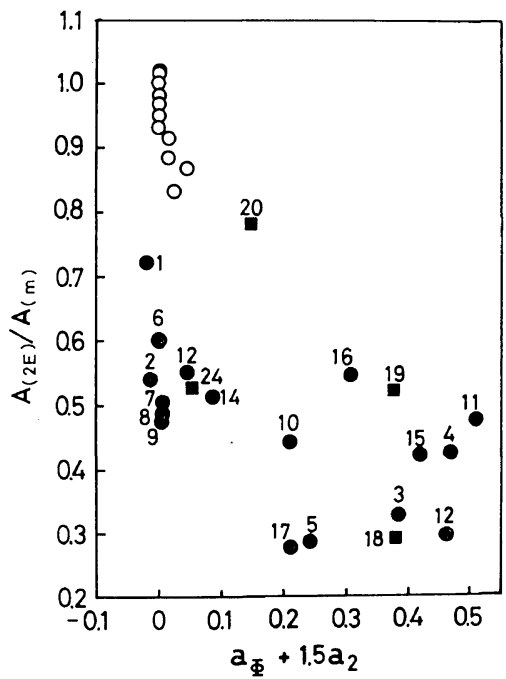

Figure 9. Plot of the ratio $A_{(2 \mathrm{E})} / A_{(\mathrm{m})}$ against $a_{\Phi}+$ $1.5 a_{2}: \bigcirc$, vinyl-type polymers ${ }^{18-24} ; \bullet$, cellulose and its derivatives; $\mathbf{a}$, amylose and its derivatives. Numbers 1-20 have the same meanings as those in Figure 1; 24, ATC in pyridine. ${ }^{57,81}$ 


\section{Unperturbed Dimensions of Cellulose Derivatives}

Table V. Conformation parameter $\sigma$ and characteristic ratio $C_{\infty}$ of cellulose, amylose and their derivatives

\begin{tabular}{|c|c|c|c|c|c|}
\hline Polymer & Solvent & $\begin{array}{c}A_{(\mathrm{m})} \times 10^{8 \mathrm{a}} \\
(\mathrm{cm})\end{array}$ & $\begin{array}{l}A_{\mathrm{f}} \times 10^{8 \mathrm{~b}} \\
\quad(\mathrm{~cm})\end{array}$ & $\sigma$ & $C_{\infty}$ \\
\hline \multirow[t]{2}{*}{ Cellulose } & Cadoxen & 1.71 & 0.614 & 2.78 & 15.8 \\
\hline & $\mathrm{FeTNa}$ & 2.39 & 0.614 & 3.89 & 30.9 \\
\hline $\mathrm{CTN}(N=13.9 \%)$ & Acetone & 2.43 & 0.456 & 5.33 & 57.8 \\
\hline$(N=13.6 \%)$ & Acetone & 2.08 & 0.460 & 4.52 & 41.6 \\
\hline $\mathrm{CN} \quad(N=12.9 \%)$ & Acetone & 1.86 & 0.470 & 3.95 & 31.9 \\
\hline $\mathrm{CA} \quad(\mathrm{AC}=55.3 \%)$ & Acetone & 1.73 & 0.481 & 3.60 & 2.63 \\
\hline \multirow[t]{3}{*}{ СТCp } & DMF & 2.02 & 0.366 & 5.52 & 62.2 \\
\hline & $1-\mathrm{Cl}-\mathrm{N}$ & 1.91 & 0.366 & 5.22 & 55.6 \\
\hline & Dioxane/water & 1.90 & 0.366 & 5.19 & 55.0 \\
\hline \multirow[t]{5}{*}{ CTC } & Anisol & $0.81_{8}$ & 0.344 & 2.38 & 11.5 \\
\hline & Cyclohexanol & $0.84_{1}$ & 0.344 & 2.44 & 12.2 \\
\hline & Acetone & 1.37 & 0.344 & 3.98 & 34.7 \\
\hline & Cyclohexanone & 1.35 & 0.344 & 3.92 & 32.3 \\
\hline & Dioxane & 1.85 & 0.344 & 5.38 & 59.0 \\
\hline $\mathrm{MC}(\mathrm{DS}=2)$ & Water & 2.32 & 0.567 & 4.09 & 34.2 \\
\hline $\mathrm{NaCMC}(\mathrm{DS}=0.88)$ & $\mathrm{NaCl}(\mathrm{I} \rightarrow \infty)$ & 1.46 & 0.502 & 2.91 & 17.2 \\
\hline $\mathrm{HEC}(\mathrm{DS}=1)$ & Water & 2.25 & 0.494 & 4.55 & 34.0 \\
\hline $\mathrm{EHEC}(\mathrm{DS}=2)$ & Water & 2.30 & 0.510 & 4.51 & 41.4 \\
\hline $\mathrm{NaCX}(\mathrm{DS}=0.78)$ & $1-M \mathrm{NaOH}$ & 3.79 & 0.505 & 7.50 & 114.7 \\
\hline Amylose & DMSO & 1.55 & 0.476 & 3.26 & 21.5 \\
\hline ATA & Nitromethane & 1.08 & 0.357 & 3.02 & 18.6 \\
\hline \multirow[t]{2}{*}{ ATC } & Pyridine/water & $0.99_{5}$ & 0.267 & 3.73 & 28.4 \\
\hline & Pyridine & 1.07 & 0.267 & 4.01 & 32.9 \\
\hline
\end{tabular}

a The most reliable value of $A$ is determined as an average of those estimated by methods $2 \mathrm{~A}, 2 \mathrm{~B}, 2 \mathrm{C}\left(a_{2}=0\right)$, or $2 \mathrm{D}\left(a_{2} \neq 0\right)$ and $2 \mathrm{G}$.

b $A_{\mathrm{f}}$ is $A$ of the freely rotating chain which the length of virtual bond of $\mathrm{Cl}$ chair form of cellulose and its derivatives and amylose and its derivatives are $5.47 \AA$ and $4.25 \AA$, respectively, and glycosidic bridge angle is $110^{\circ}$.

between the hydrodynamic approach (method $2 \mathrm{G}$ ) and the thermodynamic approach (methods 2C and 2D) is generally achieved for any actual system by correcting the non-gaussian nature of chain and the draining effect on $[\eta]$. In this sense, the most reliable value of $A$ must be an average value of $A$ estimated by methods $2 \mathrm{~A}, 2 \mathrm{~B}, 2 \mathrm{C}$ (in the case of $a_{2}=0$ ) or 2D (in the case of $a_{2} \neq 0$ ) and 2G. We denote this by $A_{(\mathrm{m})}$. The $A_{(\mathrm{m})}$ value thus determined is given in Table $\mathrm{V}$, in which the $A_{\mathrm{f}}$ values are also included. $\sigma$ as well as $C_{\infty}$ values are calculated from $A_{(\mathrm{m})}$ and tabulated in the fifth and sixth columns of Tables $V$, respectively.

The values of $\sigma$ for cellulose, amylose and their derivatives in solutions are substantially larger than those $(\sigma<3.0)$ of the vinyl-type polymers. Exceptional cases are celluloses in cadoxen,${ }^{30}$ CTC in anisol ${ }^{4,45}$ and in cyclohexanol, ${ }^{4,45}$ and $\mathrm{NaCMC}$ in aq. $\mathrm{NaCl}$ solution, ${ }^{49}$ for which $\sigma$ is in the range 2.0-3.0. From Table $\mathrm{V}$ it can be definitely concluded that cellulose, amylose and their derivatives are semi-flexible polymers, which have greatly extended unperturbed chain dimensions, owing to the markedly interrupted internal free rotation of the chain. Rather large differences in the unperturbed chain dimensions are observed in different solvents for CTC, where the solvent effect on $A$ obtained here is completely the same as that derived by using method $2 \mathrm{E}$ or $2 \mathrm{~F}$.

In Figure $10, a_{2}$ is plotted against $a_{\Phi}$. There is a crude negative correlation between $a_{2}$ and $a_{\Phi}$ $(r=-0.63)$. In other words, a polymer chain becomes less impermeable as the chain conformation deviates from gaussian statistics and $a_{\Phi}$ has a tendency to compensate for $a_{2}$ in eq $5^{\prime}$.

In the case of $a_{2} \neq 0$ and $a_{\Phi} \neq 0$, the exponent $a$ 


\section{K. KAMIDE and Y. MiYAZAKI}

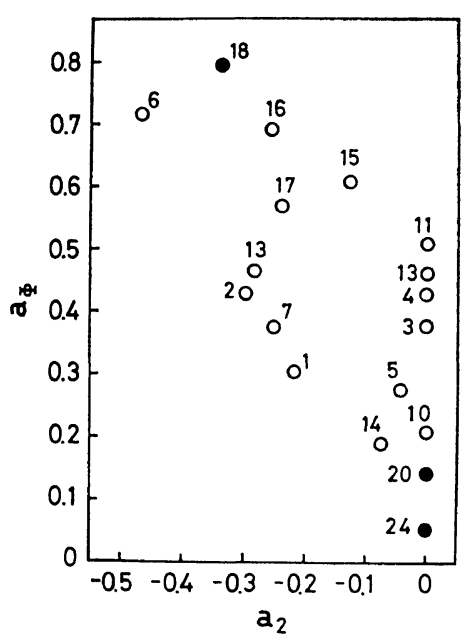

Figure 10. Correlationships between $a_{2}$ and $a_{\Phi}$ for cellulose and its derivatives (open mark) and for amylose and its derivatives (closed mark). Numbers have the same meanings as those in Figures 1 and 9.

in the MHS equation (eq 4) in Flory's theta solution, designated as $a_{\theta}$, is not always 0.5. $a_{\theta}$ is generally given by

$$
a_{\theta}=0.5+a_{\Phi}+1.5 a_{2}
$$

The value of $a_{\theta}$ was calculated from the values of $a_{2}$ and $a_{\Phi}$ given in Table III through use of eq 48 and was compared with the experimental value. The results obtained were $0.505(0.495)$ for $\mathrm{CTCp}^{43}$ in DMF, $\sim(0.524)$ for CTC in anisol, ${ }^{59} 0.544$ (0.508) for MC in water ${ }^{46}$ and $0.644(0.599)$ for ATC in pyridine-water. ${ }^{56}$ The values in parenthesis indicate the experimental values. The calculated $a_{\theta}$ value is in accordance with the experimental value if the error inherent in $a_{2}$ and $a_{\Phi}$ is considered. Thus, there are actually several experimental cases of $a_{\theta} \neq 0.5$, which provide direct evidence of the existence of either $a_{2}$ or $a_{\Phi}$ or both and even in the case $a_{\theta}=0.5$ there is a possibility that $1.5 a_{2}$ compensates for $a_{\emptyset}$.

In principle, both eq 36 and 41 give the correct value of $K_{0}$ (accordingly, $A$ ), provided that $a_{2}$ equals zero (eq 36) or $a_{2}$ is determined in advance (eq 41) and the draining parameter $X$ is accurately evaluated. In these cases, the uncertainty of $X$ value plays an important role in the determination of $A$. However, the $X$ value estimated for a given polymer-solvent system scatters to a large extent (see Tables IIa and IIb) although $X$ is inversely proportional to $a_{\Phi}$. Assuming $X$ to be constant, we determined $A$ value from the $X$ value in Table II by use of eq 36 . The $A$ value thus obtaind decreases linearly with an increase in $\log X$. The most reliable value of $A$ falls often in the scatter of the $A$ value estimated by eq 36 . This strongly suggests that the $A$ value underestimated by method $2 \mathrm{E}$ (and probably also by method $2 \mathrm{~F}$ ) increases to the true value if the draining effect is taken into account. However, from a practical point of view, employment of eq 36 and 41 is not recommended for estimating $A$, because of the low accuracy in the estimation of $X$.

Hitherto, the $A$ value obtained by methods 2B and $2 \mathrm{C}$ has been often regarded as less reliable, as compared with that by method $2 \mathrm{E}$, because it was considered that the second virial coefficient $A_{2}$ has a large experimental uncertainty for cellulose, amylose and their derivatives in solutions, for which $A_{2}$ is very small (in the order of $10^{-4} \mathrm{~cm}^{3}$. $\mathrm{mol} \cdot \mathrm{g}^{-2}$ ) and does not exhibit any significant molecular weight dependence except for $\mathrm{CTN}^{32,35}$, $\mathrm{CN}^{32,35}$ and $\mathrm{CA}^{41}$. In this paper, we examine the reliability of $A_{2}$ as follows: $A_{2}$ is usually expressed by $^{6,67}$

$$
A_{2}=\left(N_{\mathrm{A}} / 2\right) B h_{0}(z)
$$

where $h_{0}(z)$ is, for example, given by eq 27 . When the values of $A$ and $B$ are indirectly obtainable from the Baumann, BKM, SF, and KM plots, we can calculate $A_{2}$ from $A, B$ and the experimental $\left\langle S^{2}\right\rangle_{w}$ value with the aid of eq 49 and 27 . The experimental value of $A_{2}$ can be compared with the calculated one thus obtained. As is evident from Table III, Penzel-Schulz's data ${ }^{32,33}$ on CTN $(N=13.9 \%)$ and $\mathrm{CN}(N=12.9 \%)$ are most reliable. The parameters $A$ (or $K_{0}$ ) and $B$ are determined from an intercept at $M_{w}^{1 / 2}=0$ and its slope of the above plots for CTN and $\mathrm{CN}$ in acetone (Figures 4 and 6). The $A$ and $B$ values thus obtained are listed in Table VI. From these values together with the experimental $\left\langle S^{2}\right\rangle_{w}$ data, $A_{2}$ was calculated. Figure 11 shows the smooth curves of the molecular weight dependence of $A_{2}$ calculated in this manner as full (method $2 C$ ), dotted (method 2E), broken (method 2D) and chain (method 2G) lines. The experimental data points are also included in this figure. There is a considerable disagreement between the experimental points and the theoretical curve by method $2 \mathrm{E}$. 
Table VI. The parameters $A, K_{0}$ and $B$ estimated by methods $2 \mathrm{C}, 2 \mathrm{D}, 2 \mathrm{E}$, and $2 \mathrm{G}$ from Schulz-Penzel's data ${ }^{32}$ on CTN $(N=13.9 \%)$ and CN $(N=12.9 \%)$ in acetone

\begin{tabular}{|c|c|c|c|c|c|c|c|c|}
\hline \multirow[t]{2}{*}{ Polymer } & \multicolumn{2}{|c|}{$A \times 10^{8}(\mathrm{~cm})$} & \multicolumn{2}{|c|}{$K_{0} \times 10^{18}\left(\mathrm{~cm}^{2}\right)$} & \multicolumn{4}{|c|}{$B \times 10^{27}\left(\mathrm{~cm}^{3}\right)$} \\
\hline & By $2 \mathrm{C}$ & By $2 \mathrm{E}$ & By 2D & By $2 \mathrm{G}$ & By $2 \mathrm{C}$ & By $2 \mathrm{D}$ & By $2 \mathrm{E}$ & By $2 \mathrm{G}$ \\
\hline $\operatorname{CTN}(N=13.9 \%)$ & 2.43 & $0.79_{2}$ & - & 1.00 & 5.12 & 一 & 20.9 & $3.5_{7}$ \\
\hline $\mathrm{CN} \quad(N=12.9 \%)$ & 1.84 & $0.52_{2}$ & 1.85 & 0.80 & 9.35 & 10.0 & 18.2 & $7.7_{1}$ \\
\hline
\end{tabular}

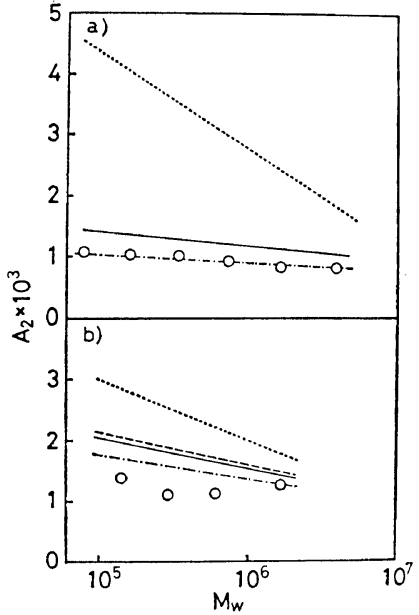

Figure 11. Second virial coefficient $\mathrm{A}_{2}$ of $\mathrm{CTN}(N=$ $13.9 \%)$ and $\mathrm{CN}(N=12.9 \%)$ in acetone ${ }^{32,33}$ : open mark, experimental data. Lines are calculated by using eq 27 and 49 from $A$ (or $K_{0}$ ) and $B$, which are estimated by methods $2 \mathrm{C}$ (full line), $2 \mathrm{D}$ (broken line), $2 \mathrm{E}$ (dotted line) and $2 \mathrm{G}$ (chain line), and the experimental $\left\langle S^{2}\right\rangle_{w}$ data.

However, the above disagreement should be remarkably improved by adopting methods 2C, $2 \mathrm{D}$, and $2 \mathrm{G}$, in the case of $\mathrm{CTN}(N=13.9 \%)$. Since in the BKM and KM plot the value of $a_{2}$, which was determined using $A_{2}$ value, was employed, the agreement between the experimental $A_{2}$ and those by method $2 \mathrm{D}$ and $2 \mathrm{G}$ does not afford in the strict sence, direct verification of the reliability of the experimental $A_{2}$. However, it seems sufficient to point out that not the absolute value, but the molecular weight dependence of $A_{2}$ contributes the $a_{2}$ value and the effect of $a_{2}$ on $A_{2}$ is very minor as is seen from Figure 10.

The linear expansion factor $\alpha_{\mathrm{s}}$ can be indirectly calculated from (1) the $A$ value by method 2E, $M_{w}$ and $\left\langle S^{2}\right\rangle_{w}$ data, (2) the $A_{(\mathrm{m})}$ value, $M_{w}$ and $\left\langle S^{2}\right\rangle_{w}$ data, and (3) the experimental data of $A_{2}$, $M_{w}$, and $\left\langle S^{2}\right\rangle_{w}$ via $\psi$. The expansion factor $\alpha_{\mathrm{s}}$ thus estimated is hereafter referred to as $\alpha_{\mathrm{s}(2 \mathrm{E})}$, $\alpha_{\mathrm{s}(\mathrm{m})}$, and $\alpha_{\mathrm{s}(\psi)}$, respectively. The relationships between $\alpha_{\mathrm{s}(2 \mathrm{E})}, \alpha_{\mathrm{s}(\mathrm{m})}$ and $\alpha_{\mathrm{s}(\psi)}$ are illustrated in Figure 12. Obviously, the relation; $\alpha_{\mathrm{s}(2 \mathrm{E})} \gg \alpha_{\mathrm{s}(\mathrm{m})}$ $\simeq \alpha_{\mathrm{s}(\psi)}$ holds for these polymers. In this respect, methods 2A, 2B, 2C (or 2D), and 2G are consistent with each other.

It has been widely recognized that the application of eq 40 or similar equations to cellulose derivatives leads to a large expansion factor $\alpha_{s}$ and to relatively small unperturbed chain dimensions. ${ }^{2}$ The inapplicability of eq 40 or similar equations is clear from the fact of $a_{2} \leq 0$ and $a_{\Phi}>0$, as repeatedly noticed in this paper. In conclusion, it can be said that the expansion factor $\alpha_{\mathrm{s}}$ is usually less than 1.3-1.4 even in good solvents. This should be additionally supported by estimating the excluded volume effect $a_{1}$ from $a$ and $a_{2}$ using eq 18 and from

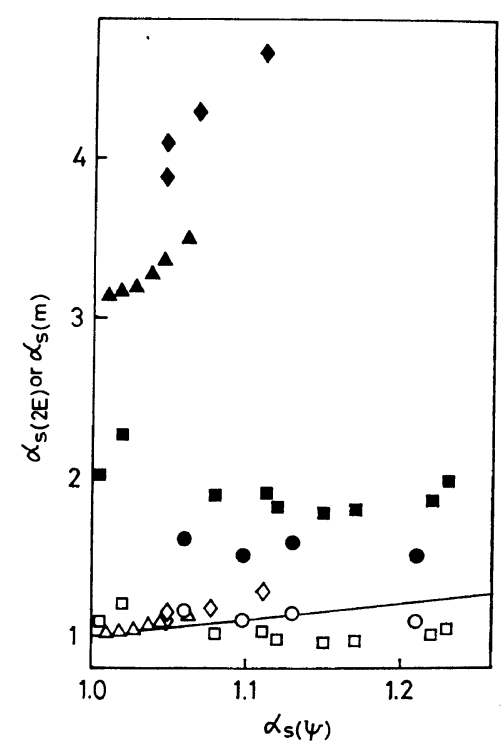

Figure 12. Comparison of $\alpha_{\mathrm{s}(2 \mathrm{E})}$ and $\alpha_{\mathrm{s}(\mathrm{m})}$ with $\alpha_{\mathrm{s}(\psi)}$ : open mark, $\alpha_{\mathrm{s}(\mathrm{m})}$; closed mark, $\alpha_{\mathrm{s}(2 \mathrm{E})} ; \square, \square$, cellulose in $\mathrm{FetNa}^{30} ; \mathrm{O}, \boldsymbol{\bullet}$, cellulose in cadoxen ${ }^{31} ; \triangle$, $\Delta, \mathrm{CTN}(N=13.9 \%)$ in acetone ${ }^{32} ; \diamond, \diamond, \mathrm{CN}(N=$ $12.9 \%$ ) in acetone. ${ }^{32,33}$ 


\section{K. KAMIDE and Y. MiYAZAKI}

$a, a_{2}$, and $a_{\Phi}$ using eq $5^{\prime}$. The values of $a_{1}$ thus determined are summarized in Table III. Among 23 polymer-solvent systems, $a_{1}$ is found to be practically zero for nineteen systems, if eq 18 is applied. This corresponds to a low $a_{1}$ value, a low $z$ value and $\alpha_{\mathrm{s}} \simeq 1.0$. For the other remaining three systems, $a_{1}>0.15$ is obserbed: Cellulose in cadoxen $\left(a_{1}=0.22\right)$, in FeTNa $\left(a_{1}=\right.$ $0.17)$ and $\mathrm{CN}(N=12.9 \%)$ in acetone $\left(a_{1}=0.18\right)$. When a large experimental error involved in $a_{1}$ $(\sim 0.1)$ is considered, $a_{1}>0.15$ for these three systems is not exceedingly larger than that expected from $\alpha_{\mathrm{s}}$ value. For example, we obtain $\alpha_{\mathrm{s}}=1.2$ for $a_{1} \simeq 0.16$ by using Voeks relation. ${ }^{68,69}$ Moreover, for these systems it was confirmed that the $\alpha_{\mathrm{s}(2 \mathrm{G})}$ or $\alpha_{\mathrm{s}(\mathrm{m})}$ value corresponds well with $A_{2}$ experimentally determined. And if eq $5^{\prime}$, which is less reliable than eq 18 , is employed, sixteen systems exhibit $a_{1} \simeq 0$. Conclusively, Table III indicates $a_{\Phi}$ generally to be a major contribution to $a$.

In the dilute solutions of cellulose, amylose and their derivatives the penetration function $\psi$ is small (accordingly $\alpha_{\mathrm{s}} \simeq 1.0$ ), but the excluded volume parameter $z$, evaluated from the slope of the SF plot, is unexpectedly large. This contradiction is yet unresolved. In this paper, $\psi$ was calculated from the experimental data of $A_{2}, M_{w}$, and $\left\langle S^{2}\right\rangle_{z}$ using of eq 21. On the other hand, $A$ and $B$ were evaluated from the intercept and the slope of the SF plot and the KM plot (the former were given in Table IV) and $z$ was calculated by eq 23 . Then, from $A$ and the experimental data of $\left\langle S^{2}\right\rangle_{z}$, $\alpha_{\mathrm{s}}$ was calculated. Using $z$ and $\alpha_{\mathrm{s}}$ thus obtained $\bar{z}$ was evaluated. The plot of $\psi$ against $\bar{z}$ for typical cellulose derivatives is illustrated as a closed circle (method 2E) and an open circle (method 2G) in Figure 13, in which the theoretical curves of Flory-Krigbaum-Orofino (FKO), ${ }^{68,69}$ modified FKO (FKOm), ${ }^{67}$ Kurata-FukatsuSotobayashi-Yamakawa (KFSY-I and KFSYII) ${ }^{70}$ and Casassa-Markovitz $(\mathrm{CM})^{71}$ are also graphed.

All points for method 2E deviate largely from all the theoretical curves, but the points of method $2 \mathrm{G}$ fall on any theoretical curve. Figure 13 also provides a support for the superiority of method $2 \mathrm{G}$. In view of the above, if method $2 \mathrm{G}$ is utilized, there is no inconsistency between $\psi$ and $\bar{z}$. The apparent contradiction mentioned-above can

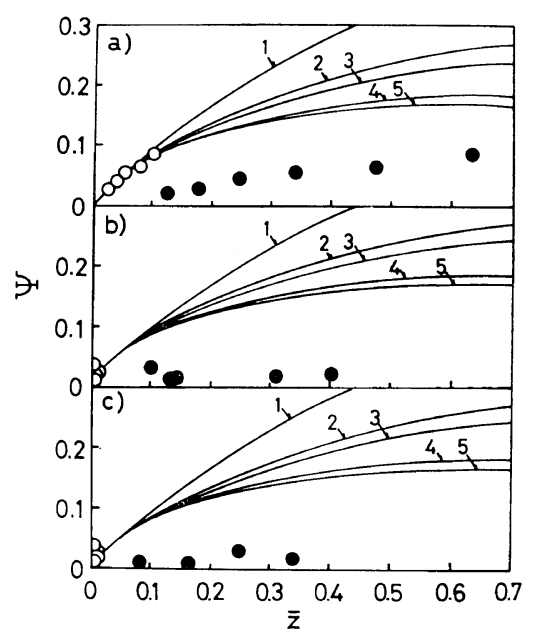

Figure 13. Plot of penetration function $\phi$ (eq 21) against $\bar{z}$; (a) $\mathrm{CTN}(N=13.9 \%)$ in acetone ${ }^{32}$; (b) CTC in dioxane, ${ }^{44}$ (c) EHEC in water. ${ }^{52}$ Full lines, theoretical relations by Flory-Krigbaum-Orofino [FKO] (curve 1), modified Flory-Krigbaum-Orofino [mFKO] (curve 2), Kurata-Fukatsu-Sotobayashi-Yamakawa [KFSY-I and KFSY--II] (curve 3 and curve 4), Casassa-Markovitz [CM] (curve 5); open mark, method $2 \mathrm{G}$; closed mark, method $2 \mathrm{E}$.

be attributed to an errorneous usage of method $2 \mathrm{E}$ in the case of $a_{2} \neq 0$ and $a_{\Phi} \neq 0$. Since method $2 \mathrm{G}$ gives $\psi$ and $\bar{z}$, which are near to zero, we can determine $\alpha_{\mathrm{s}}$ very accurately, independent of the theory of excluded volume effect chosen (in this paper, eq 27). In this connection, a large [ $\eta]$ can not be explained by a large expansion factor, but by large unperturbed chain dimensions.

As a further check on the validity of method $2 \mathrm{G}$, we calculated [ $\eta$ ] from the molecular parameters such as $A$ and $B$ by method $2 \mathrm{E}$ and $K_{\Phi}, a_{\Phi}, a_{2}, K_{0}$, and $B$ by method $2 \mathrm{G}$. The values of $[\eta]$ thus obtained, which are noted as $[\eta]_{(2 \mathrm{E})}$ and $[\eta]_{(2 \mathrm{G})}$, respectively, are compared with the experimental value $[\eta]_{(e x p)}$ in Figure 14. In this figure, the closed mark is $[\eta]_{(2 E)}$ and the open mark is $[\eta]_{(2 G)}$. The latter agrees satisfactorily with $[\eta]_{(e \times p)}$ over the whole molecular weight ranges studied, supporting method $2 \mathrm{G}$. $[\eta]_{(2 \mathrm{E})}$ deviates to a large extent from $[\eta]_{(e x p)}$ at a higher molecular weight. Figure 14 indicates that the limiting viscosity number of cellulose, amylose and their derivatives cannot be represented well in terms of only two parameters, $A$ and $B$. 


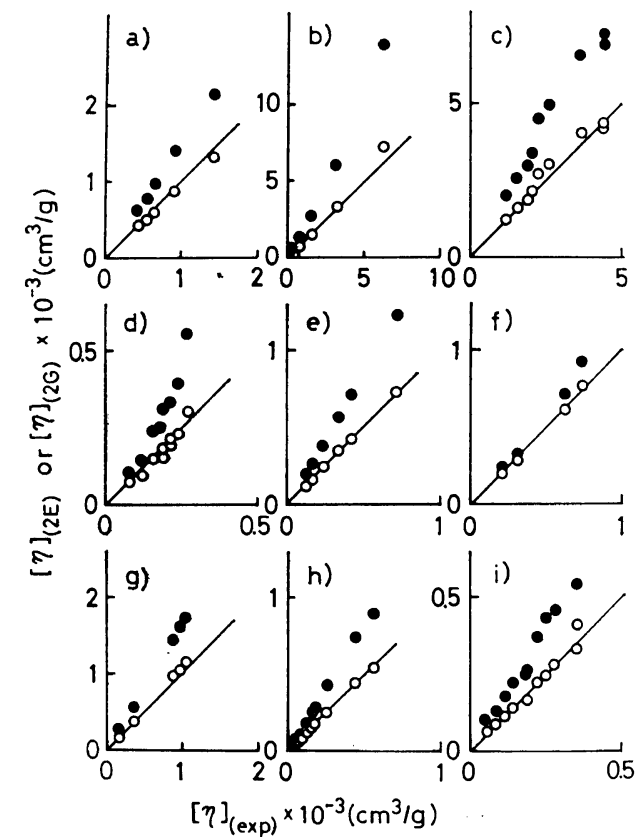

Figure 14. Comparison of $[\eta]_{(2 E)}$ and $[\eta]_{(2 G)}$ with $[\eta]_{(\exp )}: \bullet,[\eta]_{(2 \mathrm{E})} ; O,[\eta]_{(2 G)}$, (a) cellulose in cadoxene ${ }^{31}$; (b) CTN ( $N=13.9 \%)$ in acetone ${ }^{32,33}$; (c) CTN ( $N=$ $13.6 \%$ ) in acetone ${ }^{38}$; (d) CA in acetone ${ }^{41}$; (e) CTC in acetone ${ }^{44,59}$; (f) $\mathrm{NaCMC}$ in aq. $\mathrm{NaCl}^{49}$; (g) $\mathrm{HEC}$ in water ${ }^{51}$; (h) amylose in $\mathrm{DMSO}^{54}$; (i) ATC in pyridine. ${ }^{57,81}$

The variation of the radius of gyration $\left\langle S^{2}\right\rangle_{w}{ }^{1 / 2}$ for cellulose derivatives in various solvents can be virtually ascribed to the variation of the shortrange interaction parameter $A$. By comparing cellulose, amylose, CA, ATA, CTC, and ATC, we can conclude that amylose is similar to cellulose. In Figure $15, M_{\mathrm{b}}$, thus determined for cellulose and its derivatives, is plotted as a function of the molecular weight of a repeating unit $M_{b}$. An open mark means cellulose esters and a closed mark stands for cellulose ethers. There is no significant trend of $\lambda$ with $M_{\mathrm{b}}$, but $\sigma$ of $\mathrm{CN}$ has a tendency to increase with the degree of substitution.

The average value of $C_{\infty}$, calculated from $A_{(\mathrm{m})}$, for cellulose and its derivatives, is 40.5 and that from $A$ value by method $2 \mathrm{E}$ is 9 . If the rigid $\mathrm{Cl}$ chair conformations are assumed for all glycosidic residue and approximate conformational energy calculations as well as the statistical mechanical theory of chain configuration are employed, the mean glycosidic bridge angle $\beta$ corresponding for

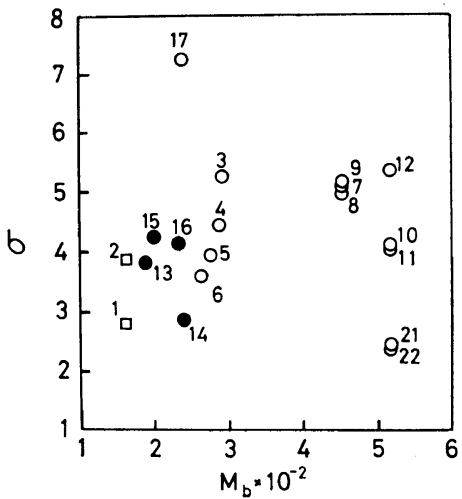

Figure 15. Effect of the molecular weight of a repeating unit $M_{\mathrm{b}}$ on the conformation parameter $\sigma$ for cellulose $(\square)$, cellulose ester $(O)$, and cellulose ether (๑). Numbers have the same meanings as those in Figures 1 and 2.

$C_{\infty}=40.5$ is estimated from Figure 2 of ref 72 to be $117^{\circ}$ and $\beta$ value for $C_{\infty}=9$ is $126^{\circ}$. The former $\beta$ value is in close agreement with the experimental data $\left(117.5^{\circ 73}\right.$ and $\left.116.5^{\circ 74}\right)$, obtained by the crystallography, suggesting the high reliability of the $A_{(\mathrm{m})}$ values evaluated here. It should be remembered that the theoretical calculations of $C_{\infty}$ were based on the unsubstituted cellulose and the values of $C_{\infty}$ in Table $\mathrm{V}$ are mainly for cellulose derivatives. The more detailed comparison of the theory and experiment on $C_{\infty}$ is beyond the scope of the present work.

\section{CONCLUSION}

(1) The partially free draining effect on hydrodynamic properties, including limiting viscosity number, exists significantly $\left(a_{\Phi}>0\right)$.

(2) The spacial distribution of segments is often non-gaussian $\left(a_{2} \lesssim 0\right)$. With decreasing molecular weight the polymer chain becomes stiffer.

(3) The fact of $a_{\Phi}>0$ and $a_{2}<0$ indicates clearly the inapplicability of the SF plot for estimating short-range interaction parameter $A$.

(4) If both the free draining effect and nongaussian nature of a chain are reasonably taken into account, the reliable parameter $A$ can be determined by using the thermodynamic (2D) or hydrodynamic approach $(2 \mathrm{G})$, proposed here.

(5) Cellulose, amylose and their derivatives are not flexible, but semi- or inflexible polymers, 


\section{K. KAMIDE and Y. MiYAZAKI}

and their dilute solution properties can not be explained by the "two-parameter" theory whose validity was widely confirmed for numerous vinyltype polymers.

\section{REFERENCES}

1. See, for example, K. Kamide, Sen-i Gakkai Shi, 33, 101 (1977).

2. M. Kurata and W. H. Stockmayer, Fortschr. Hochpolym.-Forsch., 3, 196 (1963).

3. M. Kurata and H. Yamakawa, J. Chem. Phys., 29, 311 (1958).

4. M. L. Hunt, S. Newman, H. A. Scheraga, and P. J. Flory, J. Phys. Chem., 60, 1278 (1956).

5. K. Kamide, Makromol. Chem., 128, 197 (1969).

6. K. Kamide and T. Kawai, Kobunshi Kagaku, 19, 441 (1962).

7. See, for example, M. Kurata, "Industrial Chemistry of High Polymers" Vol. III, Modern Industrial Chemistry ser. No. 18, Asakura, 1975, Chapter 4.

8. M. Kurata, M. Fukatsu, H. Sotobayashi, and H. Yamakawa, J. Chem. Phys., 41, 139 (1964).

9. M. Fixman, ibid., 36, 3123 (1962).

10. H. Baumann, J. Polym. Sci., Polym. lett., 3, 1069 (1965).

11. T. Kawai and K. Kamide, ibid., 54, 343 (1961).

12. W. H. Stockmayer and M. Fixman, ibid., Part C, 1, 137 (1963).

13. K. Kamide and T. Kawai, Kobunshi Kagaku, 19, 441 (1962).

14. K. Kamide and T. Kawai, ibid., 20, 512 (1963).

15. K. Kamide and W. R. Moore, ibid., 21, 682 (1964).

16. K. Kamide and W. R. Moore, J. Polym. Sci., Part B, 2, 1029 (1964).

17. K. Kamide, Y. Inamoto, and G. Livingstone, Kobunshi Kagaku, 23, 1 (1966).

18. K. Kamide, A. Kataoka, and T. Kawai, Makromol. Chem., 139, 221 (1970).

19. T. Norisuye, K. Kawahara, A. Teramoto, and H. Fujita, J. Chem. Phys., 49, 4330 (1968).

20. K. Kawahara, T. Norisuye, and H. Fujita, ibid., 49, 4339 (1968).

21. T. Kato, K. Miyaso, I. Noda, T. Fujimoto, and M. Nagasawa, Macromolecules, 3, 777 (1970).

22. I. Noda, K. Mizutani, T. Kato, T. Fijimoto, and M. Nagasawa, ibid., 3, 787 (1970).

23. G. Tanaka, S. Imai, and H. Yamakawa, J. Chem. Phys., 52, 2639 (1970).

24. T. Matsumoto, N. Nishioka, and H. Fujita, $J$. Polym. Sci., Part A-2, 23, (1972).

25. J. G. Kirkwood and J. Riseman, J. Chem. Phys., 16, 565 (1948).
26. P. L. Auer and C. S. Gardner, ibid., 23, 1546 (1955).

27. B. H. Zimm, ibid., 24, 269 (1956).

28. J. E. Hearst, ibid., 37, 2547 (1962).

29. C. W. Pyun and M. Fixman, ibid., 44, 2107 (1966).

30. D. Henley, Ark. Kemi, 18, 327 (1961).

31. L. Valtasaari, Markromol. Chem., 150, 117 (1971).

32. G. V. Schulz and E. Penzel, ibid., 112, 260 (1968).

33. E. Penzel and G. V. Schulz, ibid., 113, 64 (1968).

34. G. P. Pearson and W. R. Moore, Polymer, 1, 144 (1960).

35. G. Meyerhoff, J. Polym. Sci., 29, 399 (1958).

36. M. M. Huque, D. A. Goring, and S. G. Mason, Can. J. Chem., 36, 952 (1958).

37. K. Kamide, T. Shiomi, H. Ohkawa, and K. Kaneko, Kobunshi Kagaku, 22, 785 (1965).

38. W. R. Moore and G. D. Edge, J. Polym. Sci., 47, 469 (1960).

38. F. M. Holmes and D. I. Smith, Trans. Faraday Soc., 52, 67 (1956).

40. V. M. Goluber and S. Ya. Frenkel, Vysokomol. Soedin., Ser A, 9, 1847 (1967).

41. K. Kamide, T. Terakawa, and Y. Miyazaki, unpublished results.

42. K. Kamide, H. Komatsu, T. Terakawa, and S. Ishida, unpublished results.

43. W. R. Krigbaum and L. H. Sperling, J. Phys. Chem., 64, 99 (1960).

44. V. P. Shanbhag, Ark. Kemi, 29, 1 (1968).

45. V. P. Shanbhag, ibid., 29, 139 (1968).

46. W. B. Neely, J. Polym. Sci., Part A, 1, 311 (1963).

47. K. Uda and G. Meyerhoff, Makromol. Chem., 47, 168 (1961).

48. G. Meyerhoff and N. Sutterlin, ibid., 87, 258 (1965).

49. W. Brown and D. Henley, ibid., 79, 68 (1964).

50. W. Brown and D. Henley, ibid., 108, 153 (1967).

51. W. Brown, D. Henley, and J. Ohman, ibid., 64, 49 (1963).

52. R. S. Manléy, Ark. Kemi., 9, 519 (1956).

53. B. Das, A. K. Ray, and P. K. Choudhury, J. Phys. Chem., 73, 3413 (1969).

54. J. M. G. Cowie, Markromol. Chem., 42, 230 (1961).

55. J. M. G. Cowie, J. Polym. Sci., 49, 455 (1961).

56. W. Banks, C. T. Greenwood, and J. Sloss, Makromol. Chem., 140, 109 (1970).

57. W. Banks, C. T. Greenwood, and J. Sloss, Eur. Polym. J., 7, 879 (1971).

58. V.P. Shanbhag and J. Ohman, Ark. Kem., 29, 163 (1968).

59. J. Ohman, ibid., 31, 125 (1968).

60. B. Das and P. K. Choudhury, J. Polym. Sci., Part $A-1$, 5, 769 (1967). 
61. W. Banks, C. T. Greenwood, and J. Sloss, Eur. Polym. J., 7, 263 (1971).

62. K. Kamide and A. Kataoka, Makromol. Chem., 128, 217 (1969).

63. H. Benoit and P. Doty, J. Phys. Chem., 57, 958 (1953).

64. H. Yamakawa and M. Fujii, J. Chem. Phys., 64, 522 (1976).

65. H. Yamakawa, M. Fujii, and J. Shimada, J. Chem. Phys., 65, 2371 (1976).

66. P. J. Flory, "Principles of Polymer Chemistry", Conel Univ. Press, 1953, Chapter XIV.

67. W. H. Stockmeyer, Makromol. Chem., 35, 54 (1960).
68. J. Voeks, J. Polym. Sci., 36, 333 (1959).

69. K. Kamide and T. Kawai, Kobunshi Kagaku, 20, 506 (1963).

70. P. J. Flory and W. R. Krigbaum, J. Chem. Phys., 18, 1068 (1950).

71. E. F. Casassa and H. Markovitz, ibid., 29, 493 (1958).

72. K. D. Goebel, C. E. Harvie, and D. A. Brant, Appl. Polym. Symp., 28, 671 (1976).

73. R. A. Jacobson, J. W. Wunderlich, and W. N. Lipacomb, Acta, Cryst., 14, 606 (1961).

74. S. Arnott and W. E. Scott, J. Chem. Soc., Perkin Trans. 2, 1972, 324 (1972). 